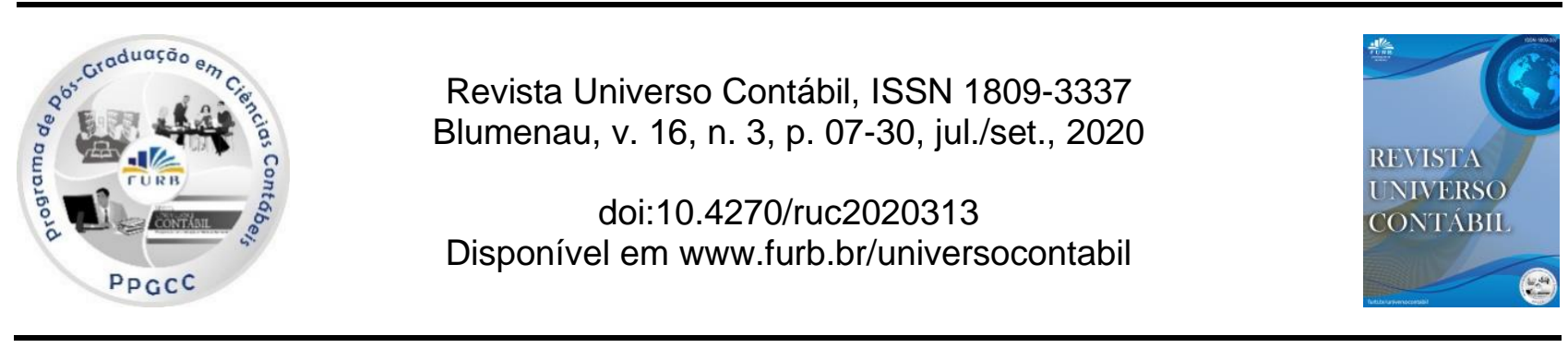

\title{
FATORES EXPLICATIVOS PARA O COMPORTAMENTO ASSIMÉTRICO DOS CUSTOS DAS EMPRESAS LISTADAS NA B3
}

\section{EXPLICATIVE FACTORS FOR ASYMMETRICAL BEHAVIOR OF COSTS FROM COMPANIES LISTED ON B3}

\section{FACTORES EXPLICATIVOS PARA EL COMPORTAMIENTO ASIMÉTRICO DE LOS COSTOS DE LAS EMPRESAS LISTADAS EN LA B3}

Recebido em: 09-07-2018

Avaliado em: 04-02-2021

Reformulado em: 05-04-2021

Aceito para publicação em: 05-04-2021

Publicado em: 15-05-2021

Editor Responsável: Franciele Beck

Fernando Richartz ${ }^{1}$

\section{RESUMO}

Esta pesquisa tem como objetivo determinar a influência dos fatores explicativos no comportamento assimétrico dos custos de empresas brasileiras. Após a revisão da literatura, com base no mapeamento de diversos fatores explicativos para a assimetria dos custos, pode-se testar 12 hipóteses de pesquisa (11 individuais e uma conjunta), por meio da técnica de regressão com dados em painel, aplicada a 617 empresas listadas na Brasil, Bolsa, Balcão (B3), no período de 1995 a 2014. Como resultados, para cada fator, tem-se que: i) existem diferenças significativas entre a assimetria dos diferentes setores; ii) o fluxo de caixa afeta a assimetria dos custos, porém, o sentido é oposto ao apresentado na literatura internacional; iii) o tamanho da empresa é um fator explicativo para a assimetria do Custo Total e do Custo dos Produtos Vendidos; iv) a intensidade do uso de ativos é um dos principais fatores que afetam os Sticky Costs; v) com três períodos consecutivos de diminuição da Receita Líquida de Vendas, os gestores reduzem os custos em proporções superiores à própria redução da Receita; vi) a influência do crescimento do Produto Interno Bruto na assimetria dos custos apresentou coeficiente significativo; vii) quando a variação da Receita é superior a 15\%, a assimetria é menor do que para variação inferior a esse percentual; viii) a legislação de proteção ao emprego; e (ix) a regulação do mercado não se confirmam para a realidade brasileira; x) o atraso nos ajustes dos custos se confirma, e o período de ajustes é de três anos; xi) o efeito da concentração do capital na assimetria dos custos é rejeitada pelos resultados dos testes. Por fim, uma hipótese conjunta foi estruturada e confirmada, com base nos 11 fatores analisados. Assim, pode-se concluir que com a junção dos fatores explicativos, que já se apresentaram significativos de forma individual, os resultados refletem de maneira mais completa o comportamento dos custos das empresas brasileiras, sobretudo em relação às causas dos Sticky Costs.

\footnotetext{
${ }^{1}$ Doutor em Contabilidade pela Universidade Federal de Santa Catarina; Professor do Departamento de Ciências Contábeis e do Programa de Pós-Graduação em Propriedade Intelectual e Transferência de Tecnologia para a Inovação PROFINIT e do Programa de Pós-Graduação em Controle de Gestão da Universidade Federal de Santa Catarina; E-mail: fernandorichartz@gmail.com

${ }^{2}$ Doutor em Engenharia de Produção pela Universidade Federal de Santa Catarina; Professor do Departamento de Ciências Contábeis e do Programa de Pós-Graduação em Contabilidade e do Programa de Pós-Graduação em Controle de Gestão da Universidade Federal de Santa Catarina; E-mail: altair@ borgert.com.br
} 
Palavras-chave: Comportamento dos custos. Sticky costs. Fatores explicativos.

\section{ABSTRACT}

This research aims to determine the influence of explanatory factors on the asymmetric cost behavior of Brazilian companies. After reviewing the literature, based on the mapping of several explanatory factors for the cost asymmetry, 12 research hypotheses (11 individual and 1 joint) can be tested using the regression technique with panel data applied to 617 listed companies at BM \& FBOVESPA, from 1995 to 2014. As a result, for each factor, we have that: i) there are significant differences between the asymmetry of the different sectors; ii) cash flow affects cost asymmetry. However, the direction is opposite to that presented in the international literature; iii) the size of the company is an explanatory factor for the asymmetry of the CT and the CPV; iv) the intensity of the use of assets is one of the main factors that affect Sticky Costs; v) with 3 consecutive periods of decrease in RLV, managers reduce costs in proportions greater than the reduction in RLV itself; vi) the influence of GDP growth on cost asymmetry showed a significant coefficient; vii) when the variation in the RLV is greater than $15 \%$, the asymmetry is less than for the variation below this percentage; viii) employment protection legislation and (ix) market regulation are not confirmed for the Brazilian reality; $\mathrm{x}$ ) the delay in adjusting costs is confirmed, and the adjustment period is 3 years; $\mathrm{xi}$ ) the test results reject the effect of capital concentration on cost asymmetry. Finally, a joint hypothesis was structured and confirmed based on the 11 factors analyzed. Thus, it can be concluded that with the combination of explanatory factors, which have already been significant individually, the results more fully reflect the cost behavior of Brazilian companies, especially about the causes of Sticky Costs.

Keywords: Cost behavior. Sticky costs. Explicative factors.

\section{RESUMEN}

Esta investigación tiene como objetivo determinar la influencia de factores explicativos en el comportamiento de costos asimétricos de las empresas brasileñas. Después de revisar la literatura, basada en el mapeo de varios factores explicativos de la asimetría de costos, se pueden probar 12 hipótesis de investigación (11 individuales y 1 conjunta) utilizando la técnica de regresión de datos de panel aplicada a 617 empresas cotizadas en BM\&FBOVESPA, de 1995 a 2014. Como resultado, para cada factor tenemos: i) existen diferencias significativas entre la asimetría de los diferentes sectores; ii) el flujo de efectivo afecta la asimetría de costos, sin embargo, la dirección es opuesta a la presentada en la literatura internacional; iii) el tamaño de la empresa es un factor explicativo de la asimetría del CT y el CPV; iv) la intensidad del uso de activos es uno de los principales factores que inciden en Sticky Cost; v) con 3 períodos consecutivos de disminución del RLV, los administradores reducen los costos en proporciones mayores que la reducción del propio RLV; vi) la influencia del crecimiento del PIB en la asimetría de costos mostró un coeficiente significativo; vii) cuando la variación en el RLV es mayor al 15\%, la asimetría es menor que para la variación por debajo de este porcentaje; viii) la legislación de protección del empleo y (ix) la regulación del mercado no están confirmadas para la realidad brasileña; $x$ ) se confirma la demora en el ajuste de costos y el período de ajuste es de 3 años; xi) los resultados de la prueba rechazan el efecto de la concentración de capital sobre la asimetría de costos. Finalmente, se estructuró y confirmó una hipótesis conjunta, a partir de los 11 factores analizados. Así, se puede concluir que con la combinación de factores explicativos, que ya han sido significativos individualmente, los resultados reflejan de manera más completa el comportamiento de costos de las empresas brasileñas, especialmente en relación a las causas de Sticky Cost.

Palabras-clave: Comportamiento de costos. Sticky costs. Factores explicativos. 


\section{INTRODUÇÃO}

Os estudos sobre comportamento dos custos, desde as primeiras publicações em periódicos na área contábil, como a de Benston (1966), por exemplo, possuíam como pressuposto básico a representação simétrica da relação entre os custos e o volume de atividades nas empresas (Anderson, Banker, \& Janakiraman, 2003; Medeiros, Costa, \& Silva, 2005; Richartz \& Borgert, 2014). Em tais estudos, comumente, os custos eram descritos como fixos ou variáveis, em resposta às alterações no volume de produção. Como o próprio nome induz, os custos fixos apresentam baixa correlação positiva com o volume de atividades. Os custos variáveis mudam proporcionalmente às alterações nas atividades, sem considerar o sentido da mudança, ou seja, sem considerar o aumento ou diminuição do referido volume. Segundo Calleja, Steliaros e Thomas (2006), esse entendimento do comportamento dos custos é uma simplificação da realidade, distante das empresas em termos de representação.

Porém, alguns estudos mudaram tal forma de representação - a denominada abordagem tradicional - em especial os de Noreen e Soderstrom (1997) e Anderson et al. (2003). Eles sugerem que a variação dos custos não depende apenas das variações do volume (medido pela receita), mas da direção dessa mudança (aumento ou diminuição). Inicialmente, Noreen e Soderstrom (1997), apesar de possuírem uma suposição diferente da abordagem tradicional, não conseguiram apresentar evidências suficientes para validá-la cientificamente. Anderson et al. (2003), em um estudo com 7.629 empresas, ao longo de 20 anos, conseguiram demonstrar que os custos não variam na mesma intensidade das receitas. Quando as receitas aumentam, os custos aumentam em uma dimensão superior do que quando as receitas diminuem, o que deu início às discussões sobre a teoria dos Sticky Costs.

Posteriormente, em uma fase mais avançada da literatura sobre os Costs Stickiness - ou custos assimétricos - composto pelos Sticky Costs e Anti-Sticky Costs, pode-se destacar os estudos de Subramaniam e Weidenmier (2003), Balakrishnan, Petersen e Soderstrom (2004), Medeiros et al. (2005), Kim e Prather-Kinsey (2010), Porporato e Werbin (2012), Weiss (2010), Balakrishnan, Labro e Soderstrom (2014), Richartz e Borgert (2014) e Marques, Santos, Lima e Costa (2014), que focam, basicamente, na identificação do fenômeno e com pouca ênfase nos fatores explicativos.

Porém, alguns estudos vão além da análise descritiva e sugerem evidências sobre variáveis explicativas para o comportamento assimétrico dos custos, cujas menções mais recorrentes na literatura apontam para:

a) estrutura de custos das empresas (Balakrishnan et al., 2004; Calleja et al., 2006; He, Teruya, \& Shimizu, 2010; Yükçü \& Özkaya, 2011; Porporato \& Werbin, 2012; Balakrishnan et al., 2014);

b) fluxo de caixa disponível (Abu-Serdaneh, 2014);

c) tamanho da empresa (Bosch \& Blandón, 2011);

d) intensidade de ativos e passivos (Anderson et al., 2003; Calleja et al., 2006; He et al., 2010; Malik, 2012; Nassirzadeh, Saei, Salehi, \& Bayegi, 2013; Abu-Serdaneh, 2014; Balakrishnan et al., 2014; Jalilian \& Elyssai, 2014);

e) decisões deliberadas dos gestores (He et al., 2010; Yasukata, 2011; Yükçü \& Özkaya, 2011; Malik, 2012; Nassirzadeh et al., 2013; Banker \& Byzalov, 2014; Banker, Byzalov, Ciftci, \& Mashruwala, 2014; Blue, Moazez, \& Khanhossini, 2014; Jalilian \& Elyssai, 2014);

f) ambiente macroeconômico (Yükçü \& Özkaya, 2011; Porporato \& Werbin, 2012; Banker, Byzalov, \& Plehn-Dujowich, 2014; Balakrishnan et al., 2014; Ibrahim, 2015);

g) magnitude das variações da receita (Subramaniam \& Weidenmier, 2003; Malik, 2012; Nassirzadeh et al., 2013);

h) legislação de proteção ao emprego (Banker, Byzalov, \& Chen, 2012; Guenther, Riehl, \& Robler, 2014); 
i) regulamentação do mercado (Yükçü \& Özkaya, 2011; Holzhacker, Krishnan, \& Mahlendorf, 2015; Kremer, 2015);

j) atraso nos ajustes de custos (Anderson et al., 2003; Calleja et al., 2006; Balakrishnan et al., 2014; Banker \& Byzalov, 2014; Banker, Byzalov, Ciftci et al., 2014); e,

k) problemas de agência (Calleja et al., 2006; Yükçü \& Özkaya, 2011; Chen, Lu, \& Sougiannis, 2012; Malik, 2012; Guenther et al., 2014; Liang, 2013; Xi, Liu, Wang, \& Liang, 2013).

Vale destacar que esses fatores se referem à junção das evidências de diversas pesquisas, cada qual aplicada em contexto e tempo diversos. Ademais, as variáveis apresentadas foram citadas como possíveis explicações, de forma isolada, em estudos de revisão teórica. Pouco foram testadas no sentido de identificar se realmente afetam o comportamento dos custos, ou mesmo se são significativas quando analisadas em conjunto. Essa carência de consolidação é observada, sobretudo, em países com economias emergentes, como no caso do Brasil, que atraem a atenção de empresas e investidores. Em suma, percebe-se que a temática trata de uma teoria em construção e que carece de desenvolvimento, em especial, com estudos voltados para o conjunto dos fatores explicativos aplicados às economias em desenvolvimento (Malik, 2012).

Apesar da quantidade limitada de estudos voltados à identificação dos fatores explicativos, alguns já demonstraram a existência dos Sticky Costs nas empresas brasileiras, como é caso de Medeiros et al. (2005), Richartz e Borgert (2014), Marques et al. (2014) e Pamplona, Fiirst, Silva, \& Zonatto (2015). Ou seja, existe uma situação que ainda carece de explicação e é considerada importante para a gestão dos negócios de acordo com Guenther et al. (2014) e Marques et al. (2014). Um caminho para a compreensão dessa situação se apresenta por meio da realização de estudos que comprovam se tais fatores explicativos para os Sticky Costs, apresentados na literatura, também se aplicam às empresas brasileiras, tanto individualmente como quando analisados em conjunto, uma vez que cada país possui características próprias que podem afetar o comportamento dos custos, conforme destacam Yükçü e Özkaya (2011).

Pelo exposto, e considerando-se que a teoria do comportamento dos custos teve, a partir de 2003, um entendimento distinto, com abertura para as discussões sobre os Sticky Costs, parte-se da premissa de que os fatores explicativos identificados na literatura internacional também afetam o nível de assimetria dos custos das empresas brasileiras, porém, em diferentes escalas. Sua junção resulta em uma explicação mais robusta para os Sticky Costs. Como as economias menos desenvolvidas ou emergentes possuem características distintas das economias desenvolvidas, onde os estudos sobre os Sticky Costs tiveram origem, busca-se resposta para a seguinte pergunta de pesquisa: qual a influência dos fatores explicativos para o comportamento assimétrico dos custos das empresas brasileiras? Assim, com base no problema de pesquisa, tem-se como objetivo determinar a influência dos fatores explicativos no comportamento assimétrico dos custos das empresas brasileiras.

A principal justificativa para a realização do trabalho se baseia em Malik (2012), que divide as pesquisas, nesta teoria, em três etapas: i) estudos que abordam as evidências de existência dos Sticky Costs; ii) estudos que apresentam algum fator explicativo/determinante dos Sticky Costs; e iii) trabalhos que abordam as consequências dos Sticky Costs para os stakeholders. Nesse sentido, constata-se que os estudos da primeira etapa, iniciados nos anos 2000, encontraram evidências comprobatórias da existência dos Sticky Costs. Assim, com a consolidação da primeira etapa, as pesquisas em nível internacional partem para a etapa de expansão desta teoria, com a identificação de fatores explicativos. É neste contexto que se desenvolve o presente estudo, que pretende contribuir para o entendimento da realidade brasileira - na qual não se encontram estudos desta natureza - e para o avanço da teoria dos Sticky Costs, que ainda possui etapas a serem exploradas.

Segundo Werbin (2011) e Yükçü e Özkaya (2011), há poucas pesquisas aplicadas ao tema de comportamento dos custos, em especial, em países com economias emergentes. Contudo, para os autores, esses países merecem investigação, porque diferem dos países desenvolvidos em muitos 
aspectos, como a volatilidade das condições macroeconômicas, regulamentações e características do mercado de trabalho, que afetam o comportamento dos custos por meio de diferentes dinâmicas. Neste sentido, a realidade brasileira é um campo oportuno para ser estudado.

Ademais, Werbin (2011) menciona que o tema de Sticky Costs é relativamente novo. Devido à sua importância, a American Accounting Association (AAA) criou, em 2009, uma seção específica para discussão no seu encontro anual, o que demonstra o interesse dos pesquisadores para com esse assunto. No mesmo sentido, conforme Krishnan (2015), as pesquisas em comportamento dos custos ganharam espaço na literatura nos últimos anos e, em especial, a assimetria dos custos se apresenta como promissora para futuras pesquisas na área contábil.

Além das justificativas apresentadas, sugerem-se duas contribuições ao tema de comportamento dos custos: uma teórica e outra prática. A principal contribuição teórica reside na consolidação dos fatores explicativos identificados na literatura, pois estes derivam de diferentes artigos, realizados em diferentes países e em tempos distintos. Assim, por não se identificar na literatura estudos que testaram as diversas variáveis em conjunto, a presente pesquisa permite um avanço científico para a teoria, com a identificação e a comprovação das variáveis que têm efeito individual e conjunto na explicação da existência dos Sticky Costs. Posteriormente, o modelo teórico gerado nesta pesquisa pode ser adaptado à realidade de diversos países, pois engloba variáveis originárias de economias com características específicas.

Do ponto de vista prático, destaca-se a possibilidade de previsão do comportamento dos custos gerada com os resultados desta pesquisa, uma vez que os analistas e gestores têm dificuldade de prever, com uma margem de segurança aceitável, o comportamento dos custos para o período seguinte, em função das características de assimetria aqui discutidas. Assim, o estudo permite que os interessados efetuem previsões em função de variáveis disponíveis de forma pública aos usuários da informação contábil. Tal situação de erros de previsão do comportamento dos custos que interferem nas previsões, por exemplo, pode ser comprovada por Kim e Prather-Kinsey (2010) que, ao considerar 3.220 analistas financeiros que fizeram previsões de vendas e lucros durante o período de 1996 a 2005, concluíram que mesmo ao acertar as previsões de vendas, de acordo com a margem de segurança definida, os analistas erram na previsão dos lucros, porque o comportamento dos custos não está relacionado linearmente com a receita. Ou seja, os custos, devido à sua parcela fixa, não variam proporcionalmente às receitas.

De forma similar, Ciftci, Mashruwala e Weiss (2016), com base em uma amostra de 107.577 observações a respeito de previsões de lucros para os anos de 1998 a 2011, afirmam que os analistas geralmente acertam as previsões de receita, mas erram as previsões de lucros, em função de não considerarem o comportamento assimétrico dos custos. Por fim, Banker e Chen (2006), Weiss (2010), Chen (2013) e Shahnazari, Talebnia e Jamei (2013) também concordam que os Sticky Costs influenciam os analistas nas previsões de lucros.

\section{FATORES EXPLICATIVOS PARA OS STICKY COSTS}

Após o estudo de Anderson et al. (2003) ocorreu uma expansão das pesquisas na temática dos Sticky Costs. Malik (2012) afirma que nos últimos anos muitos autores enfatizaram novos aspectos relacionados aos Sticky Costs, não considerados no trabalho seminal de Anderson et al. (2003). A partir dessa constatação, Malik (2012) divide a literatura sobre Sticky Costs em três categorias, evidências, fatores explicativos e consequências.

Em termos de existência da assimetria, apresenta-se na Tabela 1 as principais conclusões de algumas pesquisas abordadas no referencial teórico do presente estudo. Resumo este que demonstra o impacto no Custo Total (CT), no Custo dos Produtos Vendidos (CPV) e nas Despesas com Vendas, Gerais e Administrativas (VGA), quando a Receita Líquida de Vendas (RLV) varia 1\% para mais ou para menos. 
FATORES EXPLICATIVOS PARA O COMPORTAMENTO ASSIMÉTRICO DOS CUSTOS DAS EMPRESAS LISTADAS NA B

Tabela 1

Resumo das conclusões dos estudos referenciados

\begin{tabular}{|c|c|c|c|c|}
\hline Autores & $\begin{array}{l}\text { Período } \\
\text { de análise }\end{array}$ & Objeto de estudo & $\begin{array}{c}\text { Variáveis } \\
\text { Dependentes }\end{array}$ & Resultados para variação de $1 \%$ da RLV \\
\hline $\begin{array}{l}\text { Anderson et al. } \\
\qquad(2003)\end{array}$ & $\begin{array}{c}1979 \mathrm{a} \\
1998\end{array}$ & $\begin{array}{l}\text { Indústrias listadas } \\
\text { no Compustat - } \\
\text { USA }\end{array}$ & VGA & VGA aumentam $0,55 \%$ e diminuem $0,35 \%$ \\
\hline $\begin{array}{l}\text { Medeiros et al. } \\
(2005)\end{array}$ & $\begin{array}{l}1986 \mathrm{a} \\
2002 \\
\end{array}$ & $\begin{array}{r}\text { Empresas } \\
\text { brasileiras } \\
\end{array}$ & VGA & VGA aumentam $0,549 \%$ e diminuem $0,30 \%$ \\
\hline Calleja et al. (2006) & $\begin{array}{c}1988 \mathrm{a} \\
2004\end{array}$ & $\begin{array}{c}\text { EUA, Reino } \\
\text { Unido, França e } \\
\text { Alemanha } \\
\end{array}$ & $\mathrm{CT}$ & CT aumenta $0,97 \%$ e reduz $0,91 \%$ \\
\hline $\begin{array}{l}\text { Yükçü e Özkaya } \\
\text { (2011) }\end{array}$ & $\begin{array}{l}1987 \mathrm{a} \\
2008\end{array}$ & Empresas turcas & VGA e CT & $\begin{array}{c}\text { VGA aumentam } 0,70 \% \text { e os CT aumentam } \\
0,93 \% \text {; e reduzem } 0,51 \% \text { e } 0,81 \%, \\
\text { respectivamente }\end{array}$ \\
\hline $\begin{array}{l}\text { Porporato e Werbin } \\
\qquad(2012)\end{array}$ & $\begin{array}{c}2004 \mathrm{a} \\
2009\end{array}$ & $\begin{array}{l}\text { Bancos do Brasil, } \\
\text { Argentina e } \\
\text { Canadá }\end{array}$ & $\mathrm{CT}$ & $\begin{array}{c}\text { CT aumenta } 0,60 \% \text { (Arg.), } 0,82 \% \text { (Bra.) e } \\
0,94 \% \text { (Can.) e reduz 0,38\% (Arg.), 0,48\% } \\
\text { (Bra.) e } 0,55 \% \text { (Can.) }\end{array}$ \\
\hline $\begin{array}{l}\text { Nassirzadeh et al. } \\
(2013)\end{array}$ & $\begin{array}{l}2001 \mathrm{a} \\
2010\end{array}$ & Empresas do Iran & CPV e VGA & $\begin{array}{c}\text { CPV é simétrico; VGA aumentam } 0,44 \% \text { e } \\
\text { diminuem } 0,26 \%\end{array}$ \\
\hline $\begin{array}{c}\text { Jalilian e Elyssai } \\
(2014)\end{array}$ & $\begin{array}{l}2007 \mathrm{a} \\
2012 \\
\end{array}$ & Empresas do Iran & VGA & VGA aumentam $0,66 \%$ e diminuem $0,34 \%$ \\
\hline $\begin{array}{l}\text { Marques et al. } \\
\quad(2014)\end{array}$ & $\begin{array}{l}1995 \mathrm{a} \\
2012 \\
\end{array}$ & $\begin{array}{c}\text { Empresas da } \\
\text { América Latina }\end{array}$ & VGA & VGA aumentam $0,56 \%$ e diminuem $0,45 \%$ \\
\hline $\begin{array}{c}\text { Richartz e Borgert } \\
(2014) \\
\end{array}$ & $\begin{array}{l}1994 \mathrm{a} \\
2011 \\
\end{array}$ & $\begin{array}{r}\text { Empresas } \\
\text { brasileiras }\end{array}$ & $\mathrm{CT}$ & CT aumenta $0,96 \%$ e reduz $0,92 \%$ \\
\hline Ibrahim (2015) & $\begin{array}{c}2004 \mathrm{a} \\
2011\end{array}$ & $\begin{array}{l}\text { Empresas do } \\
\text { Egito }\end{array}$ & $\begin{array}{l}\text { VGA, CPV e } \\
\text { Custos } \\
\text { Operacionais }\end{array}$ & $\begin{array}{c}\text { VGA aumentam } 0,38 \% \text { e reduzem } 0,08 ; \mathrm{CPV} \\
\text { aumenta } 1,02 \% \text { e reduz } 0,57 \% \text {; CO aumentam } \\
0,91 \% \text { e reduzem } 1,03 \% \text {. }\end{array}$ \\
\hline
\end{tabular}

Fonte: Dados da pesquisa.

No que se refere aos fatores explicativos para a assimetria, conforme apresentado na Tabela 1, merecem destaque onze fatores que, de forma individual ou conjunta, podem explicar a realidade dos custos das empresas listadas na BM\&FBOVESPA. Tais fatores resultam nas hipóteses da pesquisa, as quais, se comprovadas, atingem o objetivo do presente estudo, de determinar a influência dos fatores explicativos no comportamento assimétrico dos custos de empresas brasileiras.

Para além dos estudos referenciados, a Tabela 2 apresenta a evolução da lógica de cálculo dos Sticky Costs, em função de um apanhado da literatura sobre o tema, desde o trabalho seminal de Anderson et al. (2003).

Conforme demonstrado, estão presentes na Tabela 2 apenas os estudos que utilizaram lógica similar à de Anderson et al. (2003), o que não exaure as formas de cálculo da assimetria, uma vez que alguns estudos utilizaram outras fórmulas, porém, com o mesmo método de análise de dados em painel. Assim, com o exposto até o momento pode-se, no capítulo de procedimentos metodológicos, efetuar o delineamento da presente pesquisa e desenvolver uma fórmula de cálculo própria, para dar resposta ao problema de pesquisa.

$\mathrm{Na}$ sequência, listam-se os fatores identificados na literatura que podem afetar o comportamento dos custos das empresas brasileiras, bem como as variáveis utilizadas para a sua mensuração. Vale destacar que, neste estudo, fatores e variáveis não se confundem, na medida em que fator é algo macro, que pode envolver mais de uma variável para fins de mensuração, como se observa na sequência.

\section{a) Estrutura de custos das empresas}

De acordo com Balakrishnan et al. (2004), Calleja et al. (2006), Yükçü e Özkaya (2011), Porporato e Werbin (2012) e Balakrishnan et al. (2014), a assimetria dos custos está diretamente relacionada com a estrutura de custos das empresas. Por exemplo, empresas com maior parcela de 
custos fixos tendem a apresentar maior assimetria, quando comparadas a empresas com maior parcela de custos variáveis. Assim, empresas de setores industriais e de serviços podem apresentar assimetria diferente, uma vez que os setores, geralmente, agrupam as empresas com estruturas produtivas com características similares. Em função do exposto, apresenta-se a seguinte hipótese:

$\mathrm{H}_{1}$ : O nível de assimetria das empresas é diferente em função do setor de atuação.

Tabela 2

Evolução da lógica de Anderson et al. (2003) para o cálculo da assimetria

$\underset{\text { (2003) }}{\text { Anderson et al. }} \log \left\{\frac{\text { Custos }_{i, t}}{\operatorname{Custos}_{i, t-1}}\right\}=\propto+\beta_{1} \log \left\{\frac{\text { Receita }_{i, t}}{\text { Receita }_{i, t-1}}\right\}+\beta_{2} *$ Dummy_Diminuição_RLV $_{-} \log _{\text {Deg }}\left\{\frac{\text { Receita }_{i, t}}{\text { Receita }_{i, t-1}}\right\}+\mu$

\section{Artigos que utilizaram o mesmo modelo de Anderson et al. (2003)}

Medeiros et al. (2005), Balakrishnan e Gruca (2008), Yükçü e Özkaya (2011), Pervan e Pervan (2012), Werbin, Vinuesa e Porporato (2012), Dalla Via e Perego (2013), Kokotakis, Mantalis, Garefalakis, Zanidakis e Galifianakis (2013), Nassirzadeh et al. (2013), Abu-Serdaneh (2014), Blue et al. (2014), Marques et al. (2014) e Pamplona et al. (2015).

\begin{tabular}{|cc|}
\hline \multicolumn{1}{|c|}{ Adaptações ao modelo de Anderson et al. (2003) } \\
\hline $\begin{array}{c}\text { Autores } \\
\begin{array}{c}\text { Subramaniam e e } \\
\text { Weidenmier } \\
(2003)\end{array}\end{array}$ & $\begin{array}{c}\text { Incorporação e divisão da magnitude das variações da RLV em } 12 \text { blocos de } 0,05 \text { (de }-30 \% \text { a } 30 \%) . \\
\text { despesas de juros/RLV. }\end{array}$ \\
\hline $\begin{array}{c}\text { Calleja et al. } \\
(2006)\end{array}$ & Inclusão de variáveis dummy para medir a magnitude das variações e as características entre setores. \\
\hline $\begin{array}{c}\text { He et al. } \\
(2010)\end{array}$ & Inclusão da intensidade de ativos, PIB, expectativa de vendas e período pós-crise. \\
\hline $\begin{array}{c}\text { Banker et al. } \\
(2012)\end{array}$ & Inclusão das variáveis legislação de proteção ao emprego, PIB e intensidade do uso de ativos. \\
\hline $\begin{array}{c}\text { Chen et al. } \\
(2012)\end{array}$ & Inclusão da governança corporativa, intensidade de MO, fluxo de caixa livre e ativos. \\
\hline $\begin{array}{c}\text { Porporato e } \\
\text { Werbin (2012) }\end{array}$ & Inclusão de variáveis para medir intensidade de ativos, PIB e magnitude das variações. \\
\hline $\begin{array}{c}\text { Análise conjunta dos fatores já incorporados à fórmula de Anderson et al. (2003), bem como os fatores desenvolvidos } \\
\text { pelos demais autores apresentados e que não utilizaram a mesma equação. }\end{array}$ \\
\hline
\end{tabular}

Fonte: Dados da pesquisa.

\section{b) Fluxo de caixa disponível}

Para Abu-Serdaneh (2014), empresas com maiores valores de fluxo de caixa disponível tendem a apresentar maior assimetria. Mesmo com declínio das receitas, e até mesmo com prejuízo contábil, se os gestores possuem caixa para pagamento dos salários e gerenciamento dos negócios, podem optar por manter os recursos, para não demonstrar a real situação da empresa. Por outro lado, quando a empresa não possui caixa, os gestores precisam eliminar recursos mais rapidamente, para poder arcar com os compromissos de curto prazo.

$\mathrm{H}_{2}$ : A assimetria está positivamente relacionada com o fluxo de caixa disponível das empresas. 


\section{c) Tamanho da empresa}

Bosch e Blandón (2011) afirmam que quanto maior o porte da empresa, menor a flexibilidade dos recursos disponíveis. Ou seja, grandes empresas possuem estrutura de custos mais rígida (fixa) do que empresas de menor porte. Em função disso, conforme já destacado na hipótese $\mathrm{H}_{1}$, estruturas mais rígidas apresentam maior assimetria dos custos, uma vez que, com reduções da receita, os custos não se ajustam na mesma proporção.

$\mathrm{H}_{3}$ : $\mathrm{O}$ tamanho da empresa está positivamente relacionado com a assimetria dos custos.

\section{d) Intensidade de ativos e passivos}

De forma semelhante ao apresentado na hipótese $\mathrm{H}_{3}$, a intensidade do uso de ativos fixos e o comprometimento das disponibilidades das empresas com recursos de terceiros pode afetar a assimetria (Anderson et al., 2003; Calleja et al., 2006; Malik, 2012; Nassirzadeh et al., 2013; AbuSerdaneh, 2014; Balakrishnan et al., 2014; Jalilian \& Elyssai, 2014). As empresas que apresentam estruturas de custos fixas, com elevada proporção de ativos imobilizados em relação ao total do ativo, tendem a apresentar maior proporção de custos fixos em relação ao custo total. Esta situação, em momentos de declínio do volume de produção, dificulta a redução dos custos, situação que gera a assimetria. Da mesma forma, quando a empresa tem seus recursos comprometidos com recursos de terceiros, os entraves causados por essa situação podem afetar a assimetria dos custos.

$\mathrm{H}_{4 a}$ : A intensidade do uso de ativos está positivamente relacionada à assimetria dos custos.

$\mathrm{H}_{4 \mathrm{~b}}$ : A intensidade do uso de passivos está positivamente relacionada à assimetria dos custos.

\section{e) Decisões deliberadas dos gestores/ Otimismo e pessimismo/ Expectativa de vendas futuras}

Em relação aos fatores explicativos apresentados na literatura, as decisões deliberadas dos gestores são intensamente discutidas e, por isso, recebem a atenção de diversos pesquisadores (Yasukata, 2011; Yükçü \& Özkaya, 2011; Malik, 2012; Nassirzadeh et al., 2013; Banker \& Byzalov, 2014; Banker, Byzalov, Ciftci et al., 2014, 2014; Jalilian \& Elyssai, 2014). São muitas as explicações do porquê de a assimetria ser resultante das decisões dos gestores, porém, as mais recorrentes se baseiam no otimismo ou pessimismo e, consequentemente, na expectativa de vendas futuras. Assim, se os gestores estão otimistas quanto às vendas do período seguinte, tendem a manter recursos e investir; por outro lado, se estão pessimistas, tendem a eliminar recursos. Segundo os autores citados, uma variável que mede essa expectativa é o comportamento das vendas dos períodos anteriores. Se a receita apresenta tendência de crescimento nos últimos anos, consequentemente, os gestores podem ficar otimistas em suas previsões para o ano seguinte. Mas, se a receita apresenta tendência de queda, os gestores agem de maneira pessimista e eliminam recursos.

$\mathrm{H}_{5 \mathrm{a}}$ : O otimismo dos gestores afeta positivamente a assimetria dos custos das empresas.

$\mathrm{H}_{5 \mathrm{~b}}$ : O pessimismo dos gestores afeta negativamente a assimetria dos custos das empresas.

\section{f) Ambiente macroeconômico/ Crescimento do PIB}

Yükçü e Özkaya (2011), Porporato e Werbin (2012), Balakrishnan et al. (2014), Banker, Byzalov, Ciftci et al. (2014) e Ibrahim (2015) ressaltam que as condições favoráveis de crescimento do PIB criam expectativas positivas nos gestores, enquanto condições de recessão geram expectativas negativas. Se a economia estiver em expansão, as empresas encontram condições favoráveis para crescimento, ao contrário de momentos de retração econômica. Assim, quando os gestores estão otimistas, conforme já exposto, tendem a manter os recursos, mesmo com reduções do volume de produção. Com isso, surgem os Sticky Costs. 
$\mathrm{H}_{6}$ : $\mathrm{O}$ ambiente macroeconômico favorável está positivamente relacionado com a assimetria dos custos das empresas.

\section{g) Magnitude das variações/ Capacidade ociosa/ Custos de ajustamento de recursos}

Conforme Subramaniam e Weidenmier (2003), Malik (2012) e Nassirzadeh et al. (2013), pequenas variações do volume de produção podem ser gerenciadas sem a necessidade de investimentos. No entanto, um aumento no volume superior a $15 \%$, por exemplo, pode não mais ser gerenciado apenas com a capacidade instalada e precisa de investimentos para ser atendido. Da mesma forma, em situação de queda de volume, pequenas variações são gerenciadas sem a necessidade de eliminação de recursos; mas para quedas bruscas de produção, os gestores podem eliminar parcela dos recursos instalados para manterem as empresas competitivas e, com isso, ajustar os custos de acordo com o volume. Essa situação acarreta em comportamento Sticky para pequenas variações e Anti-Sticky para grandes variações da RLV.

$\mathrm{H}_{7}$ : A assimetria dos custos é negativamente relacionada à magnitude das variações da RLV das empresas, em que as variações inferiores a $15 \%$ da RLV apresentam maiores Sticky Costs do que para variações superiores a $15 \%$ da RLV.

\section{h) Legislação de proteção ao emprego/ Intensidade de uso de mão de obra}

Banker et al. (2012) e Guenther et al. (2014) destacam que legislações rígidas de proteção ao emprego impossibilitam as empresas de gerenciar os recursos disponíveis, em especial, a mão de obra. Assim, nesse tipo de ambiente, os gestores ficam sem opção diante da redução de demanda, pois a estrutura de mão de obra disponível é difícil e onerosa de ser reduzida, o que, por sua vez, insere características de rigidez aos custos. Ao se vincular a intensidade do uso de mão de obra com a magnitude das variações, conforme exposto na hipótese $\mathrm{H}_{7}$, pode-se dizer que os gestores não se desfazem de uma equipe se houver pequenas variações, pois os custos de demissão são maiores que os benefícios. Porém, se houver tendência de queda, os gestores podem optar por ajustar tais recursos, uma vez que, no longo prazo, os benefícios são maiores. Diante do exposto e ao se considerar que no Brasil as empresas estão sujeitas às mesmas regras trabalhistas, aquelas que possuírem maiores recursos comprometidos com mão de obra tem, consequentemente, maior assimetria.

$\mathrm{H}_{8}$ : A intensidade do uso de mão de obra está positivamente relacionada com a assimetria dos custos.

\section{i) Regulamentação do mercado}

Yükçü e Özkaya (2011), Holzhacker et al. (2015) e Kremer (2015) afirmam que as empresas inseridas em ambientes regulados possuem menor assimetria do que empresas com mercado sem regulação. Quando os preços são impostos por órgãos reguladores, as empresas precisam adequar a estrutura produtiva aos valores fixados. Portanto, precisam contar com uma estrutura flexível de produção, uma vez que estruturas rígidas não permitem a adaptação produtiva de forma tempestiva. Por outro lado, as empresas que atuam em ambientes sem regulação e que tem poder de fixação de preços, como monopólios, por exemplo, não precisam ter a preocupação em adaptação instantânea dos custos às imposições do mercado. Portanto, podem contar com estruturas produtivas mais rígidas. Assim, a regulação do mercado, em especial nas questões de fixação de preço, afeta a estrutura produtiva das empresas e, consequentemente, a assimetria dos custos. No Brasil, essa é uma realidade, com empresas que atuam em setores com forte regulação. Contudo, não se deve confundir setores regulados por agências reguladoras, foco deste estudo, com setores com preços fixados por commodities. São exemplos de agências consideradas nesta pesquisa a Agência Nacional de Energia Elétrica (ANEEL), a Agência Nacional de Telecomunicações (ANATEL), a Agência Nacional do 
Petróleo (ANP), a Agência Nacional de Transportes Terrestres (ANTT) e a Agência Nacional de Aviação Civil (ANAC).

$\mathrm{H}_{9}$ : Empresas reguladas apresentam menor assimetria quando comparadas às empresas não reguladas.

\section{j) Atraso nos ajustes dos custos}

Quando ocorrem reduções no volume de produção, diversos são os fatores que podem influenciar o comportamento dos gestores nas tomadas de decisão, que podem optar por manter recursos ou eliminá-los. Em função dessas situações, surge ou não o comportamento assimétrico dos custos. Em algumas situações, os gestores não eliminam recursos de imediato, mas após períodos consecutivos de queda de volume, ou quando sua expectativa passa a ser pessimista. Mesmo para aqueles que optam por eliminar recursos após um período de queda de volume, os custos ainda apresentam reflexos por algum período, pois são estruturas produtivas difíceis de ser descontinuadas. Além disso, os custos dos ajustes são somados ao período em execução. Portanto, o completo ajuste dos recursos ao volume produtivo pode sofrer atraso para ser completamente executado (Anderson et al., 2003; Calleja et al., 2006; Balakrishnan et al., 2014; Banker \& Byzalov, 2014; Banker, Byzalov, Ciftci et al., 2014). Nesse contexto, quando se analisam as variações ano a ano, a assimetria tende a ser maior do que se analisada em períodos maiores, como análises em triênios (t/t-3).

$\mathrm{H}_{10}$ : A assimetria é menor quando analisados períodos agrupados de três anos.

\section{k) Problemas de agência}

De acordo com Calleja et al. (2006), Yükçü e Özkaya (2011), Chen et al. (2012), Malik (2012), Guenther et al. (2014), Liang (2013) e Xi et al. (2013), os gestores podem optar por manter recursos em momentos de queda, ou mesmo investir além do necessário para a obtenção de benefícios próprios. Assim, em função do exposto na teoria da agência, os gestores optam pela maximização dos benefícios próprios. Quando os benefícios estão atrelados ao cumprimento de metas, podem gerenciar os resultados, a fim de atingir os benefícios pretendidos. Porém, essa situação acarreta no surgimento de assimetria, uma vez que quando ocorre redução do volume de produção, deve haver, também, adequação dos recursos. Portanto, em situações em que o capital da empresa está pulverizado, os sistemas de controle são mais rígidos para preservar os interesses de ambas as partes. Em situações de concentração de capital, devido à proximidade do gestor e do sócio, tais sistemas são menos rígidos e permitem ao gestor agir com mais liberdade.

$\mathrm{H}_{11}$ : O nível de concentração de capital está positivamente relacionado aos Sticky Costs.

\section{l) Hipótese conjunta}

As hipóteses apresentadas anteriormente se referem, cada qual, a um fator explicativo. No entanto, percebe-se que existe uma intersecção entre alguns fatores e outros que são complementares. Essa situação ocorre pelo fato de que as pesquisas nessa temática foram elaboradas em contextos e tempos diversos, e as variáveis utilizadas para medir as mesmas características são distintas, porém, podem manter relação. Exemplo dessa situação é o trabalho de Bosch e Blandón (2011), que afirmam que o tamanho da empresa afeta positivamente a assimetria; e os trabalhos de Anderson et al. (2003), Calleja et al. (2006), Nassirzadeh et al. (2013), Abu-Serdaneh (2014), Balakrishnan et al. (2014) e Jalilian e Elyssai (2014), que atestam que a intensidade de ativos afeta positivamente a assimetria. Essas duas variáveis podem ser complementares para a explicação do comportamento dos custos e, quando inseridas ao modelo, possibilitam maior assertividade nas previsões. Em função disso, um modelo que junte os fatores já apresentados, ou parte deles, tende a possuir melhor poder de explicação do que fatores analisados isoladamente, conforme a seguinte hipótese: 
$\mathrm{H}_{12}$ : Os fatores explicativos, quando analisados em conjunto, apresentam resultados mais robustos do que quando analisados de maneira individual.

Assim, diante dos estudos apresentados, torna-se possível traçar um panorama das pesquisas sobre o tema e identificar soluções para o problema de pesquisa anunciado no capítulo introdutório. Nesta direção, apresenta-se na Figura 1Erro! Fonte de referência não encontrada., o mapa da literatura que incorpora a evolução do tema, bem como a condensação dos fatores explicativos até o momento discutidos.

\section{Figura 1}

Mapa da literatura

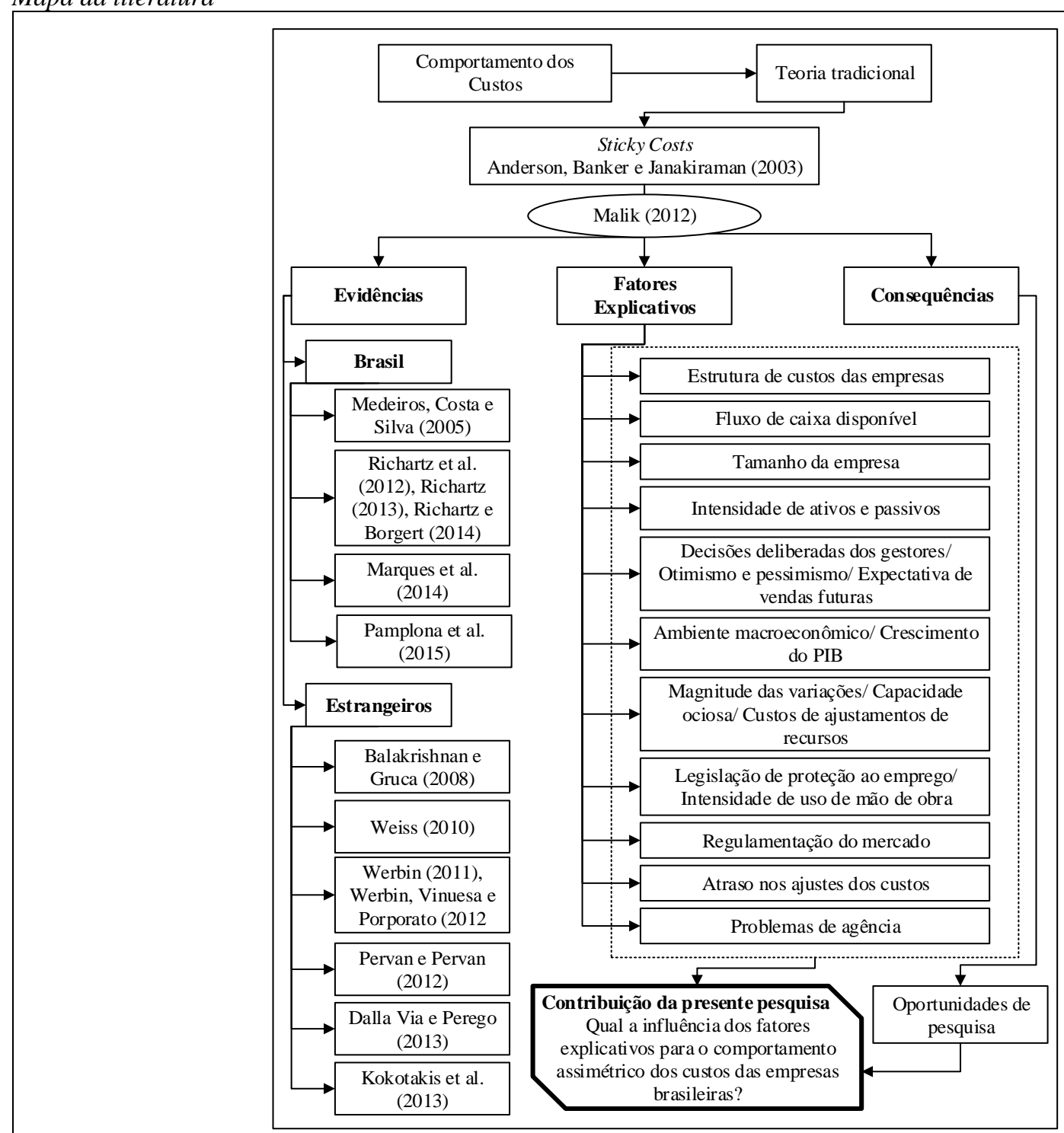

Fonte: Dados da pesquisa.

Conforme se pode observar no mapa da literatura, utiliza-se a divisão de temas proposta por Malik (2012), em que a presente pesquisa se concentra nos fatores explicativos. Portanto, com base nos métodos já utilizados pelas pesquisas apresentadas no referencial teórico, nos procedimentos metodológicos busca-se delinear as formas para testar esses possíveis fatores explicativos do comportamento assimétrico dos custos, de empresas brasileiras listadas na BM\&FBOVESPA. 


\section{PROCEDIMENTOS METODOLÓGICOS}

Para a realização deste estudo foram selecionadas as empresas com ações negociadas na BM\&FBOVESPA no período de 1995 a 2014. Excluiu-se da amostra as empresas do setor financeiro, fundos e outros de acordo com a classificação da base Economática, por possuírem regulamentações rígidas específicas, o que, em muitos casos, pode interferir na comparabilidade dos resultados. Além disso, a estrutura operacional dessas empresas é significativamente diferente das demais.

Para fazer parte da pesquisa, as empresas precisavam disponibilizar as informações, pelo menos, por quatro anos consecutivos em algum momento durante o espaço temporal investigado, pois uma das hipóteses $\left(\mathrm{H}_{10}\right)$ considera a análise de $\mathrm{t} / \mathrm{t}-3$, cujo período selecionado corresponde a 20 anos. Contudo, nem todas as empresas estavam listadas durante os 20 anos. Portanto, o número de empresas, bem como a composição da população, varia de ano para ano. Ademais, o número de empresas varia, também, em função das hipóteses testadas, pois cada uma necessita de variáveis diferentes. Assim, fazem parte somente aquelas empresas que as divulgavam.

De forma geral, tem-se 617 empresas (após a exclusão dos setores já mencionados) que em algum momento estiveram listadas na BM\&FBOVESPA e que constam nos arquivos da base Economática. Para as empresas selecionadas, coletou-se os dados necessários à realização deste estudo diretamente na base de dados Economática e no site da BM\&FBOVESPA: Receita Líquida de Vendas - RLV, Custo dos Produtos Vendidos - CPV, Despesas com Vendas - DV, Despesas Administrativas - DA, Disponibilidades, Ativo Total, Imobilizado, Passivo, Capital de Terceiros, Setor de Atuação, Concentração de Capital, Gastos com Mão de Obra e Número de Funcionários. As informações anuais, atualizadas pelo IPCA, referem-se às demonstrações de 31 de dezembro de cada ano. Para os casos de republicações, os valores foram ajustados.

Nesta pesquisa, a análise da assimetria dos custos divide-se em três etapas principais: i) análise global da assimetria com a junção do CPV, DV e DA, denominada de Custos totais (CT); ii) análise do CPV separadamente, pois este item representa, em média, 70\% do total dos itens de custos das empresas brasileiras (Richartz \& Borgert, 2014). Por isso, pode ocultar as variações assimétricas dos demais itens; e iii) análise das DV e DA, que são analisadas em conjunto, de forma similar ao estudo de Anderson et al. (2003). Porém, mesmo com três eixos de análise, a metodologia utilizada é idêntica em cada um. Destaca-se que foram retiradas as Despesas Financeiras desse conjunto, em função de não possuírem relação direta com o volume de produção, mas com a estrutura de capital das empresas. Essas despesas podem apresentar variabilidade acima de $600 \%$ de uma empresa para outra, bem como de um período para outro, conforme dados de Richartz e Borgert (2014), o que pode comprometer as análises de assimetria dos custos.

Para o cálculo da assimetria utilizou-se a técnica de análise de dados em painel, conforme já aplicada por Anderson et al. (2003), em que se captam as variações no CPV, CT e Despesas para cada $1 \%$ de variação na RLV. Utiliza-se a RLV como aproximação do volume de produção das empresas, uma vez que esta situação já está consolidada na literatura sobre os Sticky Costs. Assim, na equação (1), apresenta-se a fórmula geral para o cálculo da assimetria, a qual é aplicada tanto para o CPV quanto para o CT e as Despesas, porém, não simultaneamente. Vale destacar que o termo "custos", como variável dependente, é utilizado como elemento genérico dos três itens anteriormente mencionados.

$$
\log \left\{\frac{\operatorname{Custos}_{\mathrm{i}, \mathrm{t}}}{\operatorname{Custos}_{\mathrm{i}, \mathrm{t}-1}}\right\}=\alpha+\beta_{1} \log \left\{\frac{\text { Receita }_{\mathrm{i}, \mathrm{t}}}{\text { Receita }_{\mathrm{i}, \mathrm{t}-1}}\right\}+\beta_{2}{ }^{*} \text { Dummy_Diminuição_RLV}^{*} \log \left\{\frac{\text { Receita }_{\mathrm{i}, \mathrm{t}}}{\text { Receita }_{\mathrm{i}, \mathrm{t}-1}}\right\}+\mu
$$

Esta equação considera as variações da RLV como variáveis independentes e os custos como dependentes. Ainda, em função da constante $\alpha$, do coeficiente angular $\beta$, das variações da RLV e do erro aleatório $\mu$, consegue-se prever qual o reflexo nos custos totais quando a RLV apresenta variações. A variável "Dummy_Diminuição_RLV" assume valor 1 quando a RLV diminui do período t em relação ao t-1 e valor 0 quando a RLV aumenta nesse período, ou seja, a fórmula contempla o 
efeito da diminuição da RLV de um período para o outro. Assim, consegue-se medir a assimetria dos itens de custo (CPV, CT e Despesas) em função do aumento ou diminuição da RLV de um período para o outro. A utilização de taxas e do logaritmo dos valores, conforme Anderson et al. (2003), permite a comparabilidade das variáveis entre as empresas e reduz o potencial de heteroscedasticidade dos dados.

Para os outliers encontram-se posições diversas na literatura, porém, há um consenso pela sua exclusão. De acordo com Calleja et al. (2006), eliminam-se dos cálculos as variações da RLV superiores a $50 \%$, pois esta variação não é reflexo das operações rotineiras das empresas. Neste sentido, Subramaniam e Weidenmier (2003) utilizaram 30\% como ponto de corte, Abu-Serdaneh (2014) utilizou 50\% e Banker et al. (2012) utilizaram 50\% para os aumentos da RLV e 33\% para as reduções. Por fim, Balakrishnan et al. (2014) e Banker, Byzalov, Ciftci et al. (2014) excluíram as variações superiores a $100 \%$ de um ano para outro. Em função desse referencial, na presente pesquisa utilizou-se como ponto de corte para os outliers as variações superiores a 50\% da RLV, uma vez que variações dessa magnitude, em um período de um ano, podem significar reestruturações produtivas ou até mesmo fusões, cisões ou aquisições.

Para a análise geral da assimetria, primeiramente, efetuou-se os testes para os pressupostos do modelo: testes de normalidade, multicolineariedade, heterocedasticidade e autocorrelação. Na sequência, os testes para identificar o melhor modelo de dados em painel aplicável aos dados da presente pesquisa: efeito fixo; efeito aleatório ou POLS.

Após o atendimento dos pressupostos, calculou-se a assimetria dos custos para os Custos Totais (CT), para o Custo dos Produtos Vendidos (CPV) e, por fim, paras as Despesas com Vendas e Administrativas (DVA). Nesse cálculo, ainda, não se faz distinção entre setores, ou seja, os resultados da assimetria são a média de todas as empresas presentes nos cálculos.

Para verificar a normalidade dos dados, apresenta-se, na Figura 2Erro! Fonte de referência não encontrada., o histograma para as variáveis utilizadas nos cálculos da assimetria.

\section{Figura 2}

Normalidade dos dados

(1.5)

Fonte: Dados da pesquisa.

Os resultados gráficos apresentam curva de distribuição normal para todas as variáveis analisadas, cuja situação já era esperada em função do amplo conjunto de observações utilizadas na pesquisa, em linha com o teorema central do limite. Porém, outros pressupostos precisavam ser atendidos para se rodar a análise de dados em painel. Primeiramente, realizou-se o teste VIF 
(Variance Inflation Factor) para a identificação de multicolinearidade dos dados, ou seja, se as variáveis independentes possuíam relações lineares exatas ou aproximadamente exatas. O indício mais claro da existência da multicolinearidade é quando o $\mathrm{r}^{2}$ é alto, mas nenhum dos coeficientes da regressão é estatisticamente significativo.

Tabela 3

Teste de multicolinearidade

\begin{tabular}{|c|c|c|}
\hline Variável & VIF & 1/VIF \\
\hline log_var_rlv & 4,37 & 0,2289 \\
\hline dum_d_1_rlv & 5,02 & 0,1992 \\
\hline dum_d_2_rlv & 2,31 & 0,4320 \\
\hline dum_d_3_rlv & 1,72 & 0,5819 \\
\hline Mean VIF & 3,35 & \\
\hline
\end{tabular}

Fonte: Dados da pesquisa.

Valores de VIF maiores do que 10 indicam que as variáveis independentes são altamente colineares. O 1/VIF deve ficar no intervalo entre 0 e 1, e quanto mais próximos de 1 forem os valores, menores são as chances de multicolinearidade. Portanto, ao se analisar o teste de VIF, pode-se afirmar que os dados atendem esse pressuposto de não colinearidade.

$\mathrm{Na}$ sequência, realizou-se o teste de White, para verificar as variâncias das variáveis independentes e confirmar se são homogêneas ou heterogêneas. Ocorre problemas com heterocedasticidade quando existe uma distribuição de frequência em que todas as distribuições condicionadas têm desvios padrão diferentes. Os resultados do teste indicaram que os as variâncias são heterogêneas e, portanto, fez-se necessária a correção robusta de White no momento de rodar a regressão.

Para a verificação do pressuposto de autocorrelação serial dos termos de erro, realizou-se o teste de Wooldridge. Utilizou-se como hipótese $\mathrm{H}_{0}$ a não existência de correlação serial dos termos de erro, cujos resultados indicaram um valor p de 0,1928 , o que não rejeita a hipótese nula e, portanto, assumiu-se que os dados não possuem autocorrelação.

Por fim, realizou-se os testes para identificação do modelo mais adequado aos dados das empresas pertencentes ao estudo, com três possibilidades: efeitos fixos, efeitos aleatórios ou POLS. O primeiro teste realizado foi o de Chow, para verificar a adequação entre efeitos fixos e POLS. A hipótese $\mathrm{H}_{0}$ é POLS e a hipótese $\mathrm{H}_{1}$ é efeitos fixos, cujos resultados apontaram valor p de 0,0002, ou seja, rejeitou-se o modelo de POLS.

Mesmo com a rejeição do modelo POLS, efetuou-se o teste LM de Breusch e Pagan, em que a hipótese $\mathrm{H}_{0}$ é o modelo POLS e a hipótese $\mathrm{H}_{1}$ é efeitos aleatórios, cujos resultados apontaram para valor p de 0,0015 , ou seja, rejeitou-se novamente o modelo POLS. Portanto, ao se relacionar o modelo POLS com efeitos fixos e aleatórios, o mesmo foi rejeitado em ambos os testes. Portanto, o modelo adequado aos dados é de efeitos fixos ou aleatórios.

Para identificar qual dos dois modelos que melhor se adapta aos dados, efetuou-se o teste de Hausman. Na hipótese $\mathrm{H}_{0}$ tem-se que o modelo de efeitos aleatórios é o mais indicado, enquanto na hipótese $\mathrm{H}_{1}$ é o modelo de efeitos fixos. Após a realização dos testes, o valor p é de 0,8559 e, portanto, não se rejeitou a hipótese nula, utilizando-se o modelo de efeitos aleatórios na presente pesquisa.

Identificada a assimetria dos custos das empresas, partiu-se para a análise da influência dos fatores, apresentados por meio das hipóteses, nessa assimetria. Assim, inseriu-se na fórmula geral da assimetria as variáveis para os fatores explicativos apresentados, do tipo quantitativas contínuas e do tipo dummy, cujos testes foram realizados individualmente para cada hipótese. Por fim, na hipótese $\mathrm{H}_{12}$, a qual considera que os fatores explicativos, quando analisados em conjunto, apresentam resultados mais robustos do que quando analisados de maneira individual, todas as variáveis foram inseridas no modelo e testadas conjuntamente. Então, pode-se identificar o quanto da assimetria dos custos das empresas é explicada pelos fatores abordados neste estudo. Esta análise conjunta é importante, na medida que elimina as intersecções dos fatores, bem como o resultado permite que os 
gestores consigam prever a assimetria em função das características de cada empresa. Para fins de teste de hipóteses, considerou-se aceitável um nível de significância de até 0,15 , tendo em vista a área de conhecimento que a pesquisa se insere.

Em síntese, para facilitar a compreensão da relação das hipóteses anunciadas com os Costs Stickiness - que abrangem os Sticky e os Anti-Sticky Costs - apresenta-se, na Figura 3, o sinal esperado para a relação de dependência: sinal positivo indica que quanto maior o fator explicativo, maior a assimetria; sinal negativo indica o oposto, ou seja, quanto maior o fator, menor a assimetria; e, sinal de diferença indica que a assimetria é diferente em função da presença do fator, sem se posicionar quanto ao sentido.

\section{Figura 3}

Relação esperada entre fator explicativo e assimetria dos custos

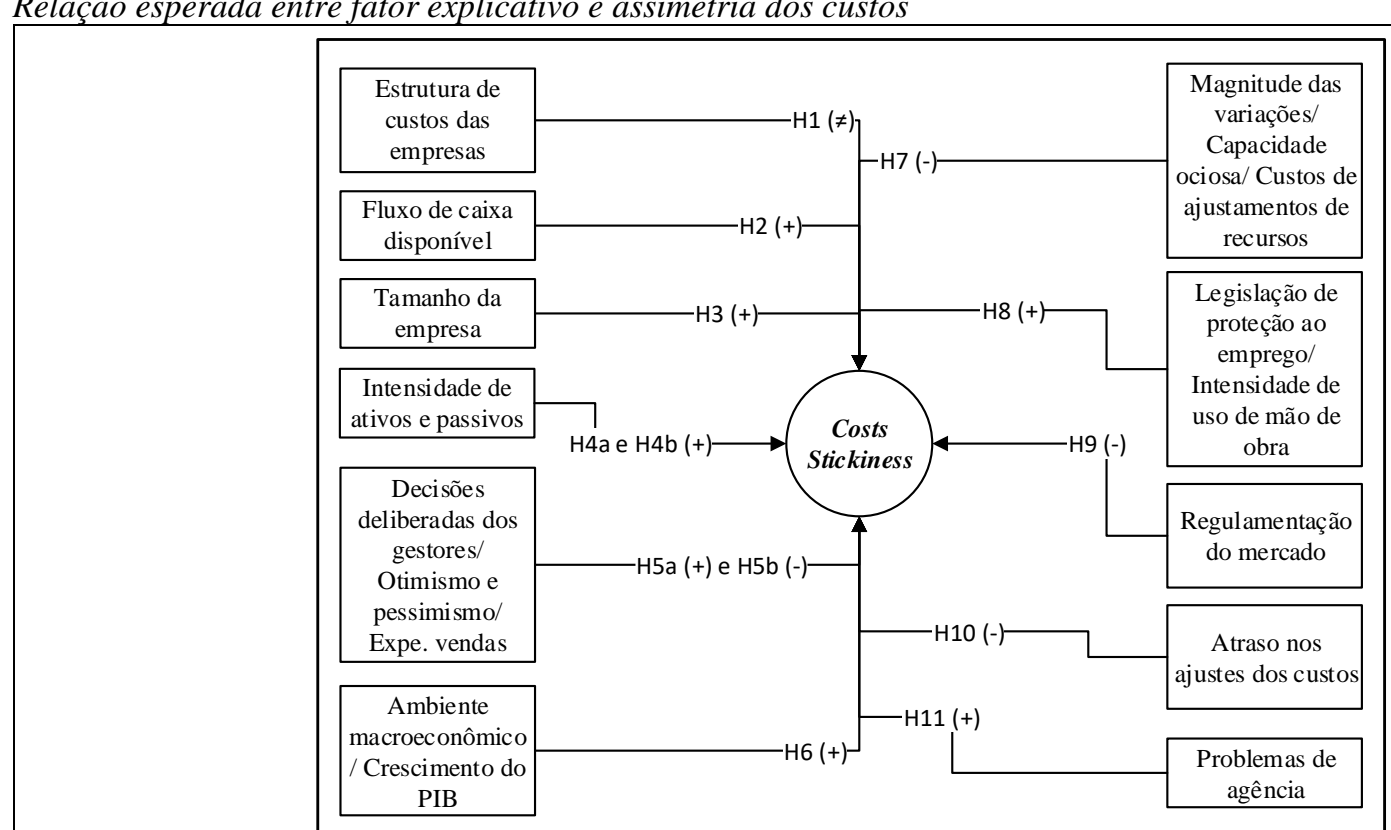

Fonte: Dados da pesquisa.

Conforme apresentado, apenas a hipótese $\mathrm{H}_{1}$ possui relação de diferença, ou seja, a assimetria é diferente em função do setor que a empresa atua. Para as demais hipóteses, ou a relação é positiva, como o tamanho da empresa, por exemplo, ou negativa, como a magnitude das variações. Cabe reforçar que a identificação da relação esperada se baseia na literatura internacional, o Brasil se apresenta como um ambiente distinto para a aplicação. Portanto, nem todas as relações podem se concretizar.

\section{APRESENTAÇÃO E ANÁLISE DOS DADOS}

Este capítulo destina-se a apresentação da assimetria dos custos de empresas listadas na BM\&FBOVESPA e da relação dos fatores explicativos com a variável dependente, para identificar os que mais contribuem para a existência dos Sticky Costs, tanto individualmente, quanto em conjunto.

\subsection{Análise da assimetria geral}

A abordagem adaptada de Anderson et al. (2003) capta o quanto os Custos aumentam quando a RLV aumenta 1\%, e quanto os Custos diminuem quando a RLV diminui na mesma proporção. Portanto, quando os custos não diminuem na mesma proporção em que aumentam, tem-se a presença 
dos Sticky Costs. Com a utilização da equação (1), de acordo com os parâmetros definidos nos procedimentos metodológicos, chegou-se aos resultados expostos na Tabela 4.

Tabela 4

Resumo do impacto nos itens de custos para variações de $1 \%$ na RLV

\begin{tabular}{|c|c|c|c|c|c|c|}
\hline \multirow{2}{*}{ Item de Custo } & \multicolumn{2}{|c|}{ Variação de $1 \%$ na RLV } & \multirow{2}{*}{$\mathbf{p}>\mathbf{z}$} & \multirow{2}{*}{$\mathbf{r}^{2}$} & \multirow{2}{*}{\multicolumn{2}{|c|}{ Assimetria }} \\
\hline & Aumento & Redução & & & & \\
\hline Custo Total & 0,74 & 0,68 & 0,06 & 0,68 & $-0,06$ & Sticky Costs \\
\hline $\mathrm{CPV}$ & 0,95 & 0,80 & 0,06 & 0,29 & $-0,15$ & Sticky Costs \\
\hline Despesas & 0,37 & 0,46 & 0,09 & 0,19 & 0,09 & Anti-Sticky Costs \\
\hline
\end{tabular}

Fonte: Dados da pesquisa.

Conforme a Tabela 4, os resultados apontam que quando a RLV aumenta 1\%, o CT aumenta $0,74 \%$. Porém, quando a RLV reduz $1 \%$, esses mesmos custos reduzem apenas $0,68 \%$. Ou seja, os custos totais das empresas brasileiras possuem comportamento sticky, cujos números derivam de 3.203 observações ao longo dos 20 anos analisados. Com coeficiente de determinação superior a 0,68 e com significância estatística comprovada para as variáveis, pode-se afirmar que o comportamento dos custos das empresas pesquisadas segue a mesma tendência das principais pesquisas realizadas no tema em nível mundial.

Em relação às análises da assimetria, somente para o CPV, destacam-se os estudos de Nassirzadeh et al. (2013), em que o CPV é simétrico, e de Ibrahim (2015), em que o CPV aumenta $1,02 \%$ e reduz $0,57 \%$ para $1 \%$ de variação na RLV. Assim, na presente pesquisa, o comportamento é similar aos achados de Ibrahim (2015), com presença de Sticky Costs para o CPV, de acordo com a abordagem proposta por Anderson et al. (2003). Resumidamente, para cada 1\% de aumento da RLV de um período para outro, o CPV aumenta $0,95 \%$. Portanto, para cada um real de aumento nas vendas, o Custo dos Produtos Vendidos aumenta 95 centavos. Porém, se as vendas reduzem 1\%, a redução do CPV é de apenas $0,80 \%$, ou seja, redução de 80 centavos para cada um real de diminuição na receita.

Por fim, as Despesas com Vendas e Administrativas apresentam comportamento distinto do CPV e do CT, as quais aumentam $0,37 \%$ para $1 \%$ de aumento da RLV e reduzem $0,46 \%$ com a redução de $1 \%$ da receita. Tal situação é citada na literatura como Anti-Sticky Costs, conforme mencionam Weiss (2010) e Banker, Byzalov, Ciftci et al. (2014). Mesmo com assimetria de 9 centavos para cada real de variação das receitas, não chega a influenciar de maneira significativa na assimetria do CT, uma vez que, em sua composição, o CPV corresponde a $69 \%$ e, conforme já verificado, apresentou comportamento Sticky.

\subsection{Análise individual dos fatores explicativos}

Os fatores explicativos identificados na literatura internacional e aplicados à realidade brasileira se comportam de maneira distinta quanto à influência na assimetria dos custos. No geral, os fatores interferem na assimetria dos custos e precisam ser considerados nos modelos de gestão das empresas. Contudo, o foco da pesquisa é identificar os fatores que influenciam a existência dos Sticky Costs, ou seja, apenas para um lado da assimetria. Neste caso, nem todos os fatores se comportam como o esperado na formulação das hipóteses, que se fundamentam em conclusões de estudos internacionais.

Tal situação já era prevista por Yükçü e Özkaya (2011), os quais afirmam que existe diferença entre países, em especial, em economias emergentes, em que os mercados não são tão consolidados quanto em países desenvolvidos. Portanto, apresenta-se na Tabela 5 o resultado dos testes de hipóteses, realizados para facilitar a compreensão da pesquisa de forma abrangente, cujos fatores explicativos podem afetar a assimetria positivamente ou negativamente, conforme já destacado. 
Tabela 5

Resultado dos testes de hipóteses para os fatores explicativos

\begin{tabular}{|c|c|c|c|}
\hline Hipótese & \begin{tabular}{|c|} 
Item \\
analisado
\end{tabular} & Resultado & $\begin{array}{l}\text { Conclusão do } \\
\text { teste de hipótese }\end{array}$ \\
\hline \multirow{3}{*}{$\begin{array}{l}\mathrm{H}_{1} \text { : O nível de assimetria das empresas é diferente em função } \\
\text { do setor de atuação. }\end{array}$} & CT & de $-0,28$ até 0,19 & Aceita \\
\hline & CPV & de $-0,56$ até 0,18 & Aceita \\
\hline & DVA & de $-0,52$ até 0,39 & Aceita \\
\hline \multirow{3}{*}{$\begin{array}{l}\mathrm{H}_{2} \text { : A assimetria está positivamente relacionada com o fluxo } \\
\text { de caixa disponível das empresas. }\end{array}$} & CT & 0,2593 & Aceita \\
\hline & $\mathrm{CPV}$ & $-0,0912$ & Rejeita \\
\hline & DVA & 0,1333 & Aceita \\
\hline \multirow{3}{*}{$\begin{array}{l}\mathrm{H}_{3}: \mathrm{O} \text { tamanho da empresa está positivamente relacionado à } \\
\text { assimetria dos custos. }\end{array}$} & CT & $-0,0439$ & Aceita \\
\hline & $\mathrm{CPV}$ & $-0,0700$ & Aceita \\
\hline & DVA & 0,1154 & Rejeita \\
\hline \multirow{3}{*}{$\begin{array}{l}\mathrm{H}_{4 \mathrm{a}} \text { : A intensidade do uso de ativos está positivamente } \\
\text { relacionada à assimetria dos custos. }\end{array}$} & $\mathrm{CT}$ & $-0,1469$ & Aceita \\
\hline & CPV & $-0,1031$ & Aceita \\
\hline & DVA & $-0,1678$ & Aceita \\
\hline \multirow{3}{*}{$\begin{array}{l}\mathrm{H}_{4 \mathrm{~b}} \text { : A intensidade do uso de passivos está positivamente } \\
\text { relacionada à assimetria dos custos. }\end{array}$} & CT & 0,0754 & Rejeita \\
\hline & $\mathrm{CPV}$ & 0,2553 & Rejeita \\
\hline & DVA & 0,0055 & Rejeita \\
\hline \multirow{3}{*}{$\begin{array}{l}\mathrm{H}_{5 \mathrm{a}}: \mathrm{O} \text { otimismo dos gestores afeta positivamente a assimetria } \\
\text { dos custos das empresas. }\end{array}$} & CT & 0,1401 & Rejeita \\
\hline & CPV & 0,1131 & Rejeita \\
\hline & DVA & 0,1619 & Rejeita \\
\hline \multirow{3}{*}{$\begin{array}{l}\mathrm{H}_{5 \mathrm{~b}} \text { : O pessimismo dos gestores afeta negativamente a } \\
\text { assimetria dos custos das empresas. }\end{array}$} & CT & 0,0980 & Aceita \\
\hline & $\mathrm{CPV}$ & 0,0654 & Rejeita \\
\hline & DVA & 0,1612 & Aceita \\
\hline \multirow{3}{*}{$\begin{array}{l}\mathrm{H}_{6}: \mathrm{O} \text { ambiente macroeconômico favorável está positivamente } \\
\text { relacionado com a assimetria dos custos das empresas. }\end{array}$} & $\mathrm{CT}$ & $-0,0228$ & Aceita \\
\hline & $\mathrm{CPV}$ & $-0,0246$ & Aceita \\
\hline & DVA & $-0,0214$ & Aceita \\
\hline $\begin{array}{l}\mathrm{H}_{7} \text { : A assimetria dos custos é negativamente relacionada à } \\
\text { magnitude das variações da RLV. }\end{array}$ & CPV & $\begin{array}{c}\text { até } 15 \%:-0,2391 \\
\text { mais de } 15 \%: 0,2391\end{array}$ & Aceita \\
\hline \multirow{3}{*}{$\begin{array}{l}\mathrm{H}_{8}: \text { A intensidade do uso de mão de obra está positivamente } \\
\text { relacionada com a assimetria dos custos. }\end{array}$} & $\mathrm{CT}$ & 0,0972 & Rejeita \\
\hline & $\mathrm{CPV}$ & $-0,1723$ & Aceita \\
\hline & DVA & 0,1820 & Rejeita \\
\hline \multirow{3}{*}{$\begin{array}{l}\mathrm{H}_{9} \text { : Empresas reguladas apresentam menor assimetria quando } \\
\text { comparadas às empresas não reguladas. }\end{array}$} & $\mathrm{CT}$ & $-0,0936$ & Rejeita \\
\hline & CPV & $-0,2270$ & Rejeita \\
\hline & DVA & $-0,1175$ & Rejeita \\
\hline \multirow{3}{*}{$\begin{array}{l}\mathrm{H}_{10} \text { : A assimetria é menor quando analisados períodos } \\
\text { agrupados de } 3 \text { anos. }\end{array}$} & $\mathrm{CT}$ & 0,0113 & Rejeita \\
\hline & $\mathrm{CPV}$ & 0,0759 & Aceita \\
\hline & DVA & 0,1026 & Aceita \\
\hline \multirow{3}{*}{$\begin{array}{l}\mathrm{H}_{11} \text { : O nível de concentração de capital está positivamente } \\
\text { relacionado aos Sticky Costs. }\end{array}$} & $\mathrm{CT}$ & 0,1425 & Rejeita \\
\hline & $\mathrm{CPV}$ & 0,1426 & Rejeita \\
\hline & DVA & 0,0198 & Rejeita \\
\hline
\end{tabular}

Fonte: Dados da pesquisa.

Em relação aos resultados demonstrados na Tabela 5, pode-se inferir os seguintes comentários:

$\checkmark$ A hipótese $\mathrm{H}_{1}$ se confirmou e existem diferenças significativas entre a assimetria dos setores. Portanto, esta variável deve ser considerada nos cálculos dos Sticky Costs, o que corrobora os estudos de Balakrishnan et al. (2004), Calleja et al. (2006), He et al. (2010), Yükçü e Özkaya (2011), Porporato e Werbin (2012) e Balakrishnan et al. (2014).

$\checkmark$ No Brasil, o Fluxo de Caixa, hipótese $\mathrm{H}_{2}$, afeta a assimetria dos custos. Porém, a hipótese foi refutada, uma vez que o sentido da assimetria é oposto ao apresentado na literatura internacional; enquanto a teoria preconiza uma relação Sticky, neste estudo constatou-se comportamento Anti-Sticky. Assim, a contribuição desta hipótese foi demonstrar que, no Brasil, o comportamento dos custos é diferente dos demais países até então investigados no âmbito dos Sticky Costs, na medida em que o ambiente regulatório diferenciado pode impactar diretamente 
nesse fator. Ainda, essa situação pode estar associada aos custos de ajustamento, como multas por demissões sem justa causa, por exemplo, em que empresas com disponibilidades têm condições de efetuar os ajustes e, consequentemente, reduzir custos em momentos de declínio de receitas (Subramaniam \& Weidenmier, 2003; Malik, 2012; Nassirzadeh et al., 2013; Richartz \& Ensslin, 2013).

$\checkmark \mathrm{O}$ tamanho da empresa, hipótese $\mathrm{H}_{3}$, medido pelo ativo, foi um fator explicativo válido para a assimetria do CT e do CPV, o que confirma a hipótese formulada, em que quanto maior o tamanho da propriedade, maior é a assimetria dos custos, conforme já constataram Bosch e Blandón (2011). Assim, este fator apresentou alinhamento entre a literatura internacional e a realidade brasileira.

$\checkmark$ A hipótese $\mathrm{H}_{4}$, que aborda a intensidade do uso de ativos e passivos, apresentou resultados robustos que permitem concluir que a imobilização das empresas (AI/A) é um dos principais fatores que afetam os Sticky Costs. Coeficientes de -0,14 para o CT, -0,10 para o CPV e -0,16 para as DVA demonstraram consistência nas conclusões e alinhamento com os resultados de Anderson et al. (2003), Calleja et al. (2006), He et al. (2010), Malik (2012), Nassirzadeh et al. (2013), Abu-Serdaneh (2014), Balakrishnan et al. (2014) e Jalilian e Elyssai (2014). Por outro lado, o comprometimento do capital com recursos de terceiros não afeta a existência dos Sticky Costs, situação também observada no estudo de Abu-Serdaneh (2014).

$\checkmark$ O pessimismo dos gestores, apresentado na hipótese $\mathrm{H}_{5}$, afeta o comportamento dos custos, conforme exposto na literatura. Com três períodos consecutivos de diminuição da RLV, os gestores reduzem os custos em proporções superiores a própria redução da RLV, uma vez que mantinham custos acumulados de períodos anteriores, conforme He et al. (2010), Yasukata (2011), Yükçü e Özkaya (2011), Malik (2012), Nassirzadeh et al. (2013), Banker e Byzalov (2014), Banker, Byzalov, Ciftci et al. (2014), Blue et al. (2014) e Jalilian e Elyssai (2014). A principal contribuição desta hipótese, aplicada à realidade brasileira, foi a constatação de que o otimismo não afeta a assimetria dos custos e que, portanto, apenas o pessimismo deve ser considerado.

$\checkmark$ A hipótese $\mathrm{H}_{6}$, que aborda a influência do crescimento do PIB na assimetria dos custos, também apresentou resultados consistentes. Coeficientes próximos a -0,02 para o CT, CPV e DVA e com $\mathrm{r}^{2}$ superior a 0,65 para o CT indicam que períodos de crescimento do PIB influenciam os Sticky Costs, exatamente como proposto na literatura internacional por Yükçü e Özkaya (2011), Porporato e Werbin (2012), Balakrishnan et al. (2014), Banker, Byzalov, Ciftci et al. (2014) e Ibrahim (2015).

$\checkmark$ Da mesma forma, a hipótese $\mathrm{H}_{7}$ também se confirmou para a realidade brasileira. Quando as variações da RLV são superiores a 15\%, a assimetria é menor do que variações inferiores a esse percentual. Com variações elevadas, os gestores precisam ajustar as empresas aos novos volumes, o que exige reestruturação do processo produtivo. Situação similar, anteriormente, foi identificada por Subramaniam e Weidenmier (2003), Malik (2012) e Nassirzadeh et al. (2013).

$\checkmark$ A legislação de proteção ao emprego $\left(\mathrm{H}_{8}\right)$ e a regulação do mercado $\left(\mathrm{H}_{9}\right)$, no geral, não se confirmaram para a realidade brasileira. No caso da $\mathrm{H}_{8}$, apenas para o CPV a hipótese se confirmou, com uma significância de $15 \%$. Porém, a aceitação da hipótese está vinculada ao resultado para o Custo Total. Ou seja, diferente das conclusões de Yükçü e Özkaya (2011) e Holzhacker et al. (2015), no Brasil, esses fatores não precisam ser considerados na análise dos Sticky Costs.

$\checkmark$ A hipótese $\mathrm{H}_{10}$, que diz respeito ao atraso nos ajustes dos custos, se confirmou. Quando analisadas as variações ano a ano, o coeficiente de assimetria para o CPV foi de - 0,15 ; e quando analisadas comparativamente com t-3, o coeficiente foi de 0,07. Assim, pode-se concluir que os ajustes dos custos demoram até três anos para ser concretizados após a redução do volume de vendas, situação alinhada com os estudos de Anderson et al. (2003), Calleja et al. (2006), Balakrishnan et al. (2014), Banker e Byzalov (2014) e Banker, Byzalov, Ciftci et al. (2014). 
Por fim, a hipótese $\mathrm{H}_{11}$, que discute o efeito da concentração do capital na assimetria dos custos, foi rejeitada. Porém, apresentou números significativos (Anti-Sticky) que devem ser considerados nas decisões dos gestores. Apesar de apresentar resultados diferentes de Calleja et al. (2006), Yükçü e Özkaya (2011), Chen et al. (2012), Malik (2012), Guenther et al. (2014), Liang (2013) e Xi et al. (2013), demonstrou-se que esse fator influencia o comportamento dos custos e o grau de concentração de capital. Ainda, de acordo com Da Silva, De Sousa e Leite (2011), está diretamente relacionado com os conflitos de agência, no qual os detentores do capital agem em função da maximização de seu bem-estar.

Na sequência do estudo, com a realização da análise conjunta, é possível identificar qual a melhor combinação de variáveis para explicar a assimetria dos custos de empresas brasileiras.

\subsection{Análise conjunta dos fatores explicativos}

Após a análise dos 11 modelos individuais, definidos com base na literatura dos Sticky Costs, pode-se verificar que alguns fatores possuem maior poder explicativo do que outros. Ainda, alguns desses fatores que se apresentaram significativos podem ser complementares na explicação da assimetria dos custos. Portanto, testou-se a hipótese $\mathrm{H}_{12}$, cuja premissa é de que os fatores explicativos, quando analisados em conjunto, apresentam resultados com maior poder explicativo do que quando analisados de maneira individual.

A hipótese conjunta contempla os fatores que apresentaram significância estatística na análise individual e que aceitaram a hipótese formulada. As variáveis "setores" e "análise agrupada de 3 períodos" não são consideradas na análise conjunta, pois não são necessariamente explicações para a assimetria, mas reflexo da estrutura de custos ou dos custos de ajustamento, por exemplo.

Dessa forma, o estudo segue a lógica utilizada para os testes das análises individuais, com a apresentação dos resultados em 3 blocos: análise para o Custo Total, Custo dos Produtos Vendidos e, por fim, Despesas com Vendas e Administrativas. Na Tabela 6 verificam-se as variáveis que, conjuntamente, explicam os Sticky Costs para o CT.

Tabela 6

Análise conjunta para o Custo Total

\begin{tabular}{|c|c|c|c|c|}
\hline var_CT & coef. & std. err. & $\mathbf{z}$ & $\mathbf{p}>\mathbf{z}$ \\
\hline var_rlv & 0,7333 & 0,02 & 37,15 & $0,00 *$ \\
\hline dum_d_1_rlv & $-0,0521$ & 0,11 & 2,71 & $0,01 *$ \\
\hline ativo_log & $-0,0280$ & 0,02 & $-1,49$ & $0,14^{*}$ \\
\hline $\log \_\mathrm{AI} / \mathrm{A}$ & $-0,1338$ & 0,02 & $-6,36$ & $0,00 *$ \\
\hline dum_d_3_rlv & 0,0892 & 0,03 & 2,82 & $0,01 *$ \\
\hline var_rlv_s15 & $-0,0104$ & 0,04 & $-0,22$ & 0,82 \\
\hline var_pib & $-0,0220$ & 0,01 & $-3,45$ & $0,00 *$ \\
\hline Cons & 0,0006 & 0,00 & 0,36 & 0,72 \\
\hline $\mathrm{r}^{2}$ within & 0,6561 & \multicolumn{2}{|c|}{ Wald chi2 } & 6194,91 \\
\hline $\mathrm{r}^{2}$ between & 0,7057 & \multicolumn{2}{|c|}{ Prob > chi 2} & 0,0000 \\
\hline $\mathrm{r}^{2}$ overall & 0,6788 & & & \\
\hline
\end{tabular}

* Dados significativos para a presente pesquisa

Fonte: Dados da pesquisa.

A análise conjunta permite aos gestores se anteciparem em relação aos impactos causados nos custos das empresas, quando ocorrem variações no volume de vendas. Para o CT, a hipótese possui bom poder explicativo, pois mais de $65 \%$ da sua variação é explicada pelas sete variáveis testadas simultaneamente. Quando analisadas em conjunto, apenas a variável "variações da RLV superiores a 15\%" não apresenta significância no modelo. Provavelmente, outra variável explica melhor as mesmas características contempladas pelas variações superiores a $15 \%$. 
Portanto, pode-se concluir que a hipótese conjunta para o custo total se confirma e permite aos gestores uma análise mais ampla dos fatores que afetam a assimetria dos custos. Conforme exposto na Tabela $\mathbf{6}$, a equação 2 para decisão dos gestores pode ser apresentada da seguinte maneira:

$$
\begin{aligned}
\text { var_CT } & =0,0006+\left(0,7333 * v a r \_r l v\right)+(-0,0521 * \text { dum_d_1_rlv })+(-0,0280 \text { ativo_log*dum_d_1_rlv })+ \\
& +\left(-0,1338 * \log \_\mathrm{AI} / \mathrm{A} * \mathrm{dum} \_\mathrm{d} \_1 \_r l v\right)+\left(0,0892 * \mathrm{dum} \_\mathrm{d} \_3 \_r l v\right)+\left(-0,0220 * v a r \_p i b * d u m \_d \_1 \_r l v\right)
\end{aligned}
$$

Substituindo-se os valores das variáveis de cada empresa, chega-se ao coeficiente de variação do CT, quando a RLV reduz $1 \%$ de um período para outro. Com base nessas informações, os gestores podem efetuar previsões e saber, antecipadamente, qual é o impacto no resultado da empresa com os aumentos ou reduções do volume de vendas.

Na sequência, apresenta-se na

Tabela 7 as análises conjuntas para o CPV que, de forma individual, apresentou maior número de fatores significativos do que o CT. Porém, ao se analisar todas as variáveis, simultaneamente, percebe-se que os fatores significativos são os mesmos já apresentados para o CT. Isso direciona a pesquisa para a indicação de uma lista de fatores que explicam a assimetria das empresas brasileiras, os quais, não necessariamente, são os mesmos identificados no cenário internacional.

Tabela 7

\begin{tabular}{|c|c|c|c|c|}
\hline var_CPV & coef. & std. err. & $\mathbf{z}$ & $\mathbf{p}>\mathbf{z}$ \\
\hline var_rlv & 1,0621 & 0,12 & 8,99 & $0,00 *$ \\
\hline dum_d_1_rlv & $-0,1511$ & 0,08 & $-1,84$ & $0,06^{*}$ \\
\hline $\mathrm{AC} / \mathrm{A}$ & $-0,1726$ & 0,23 & $-0,76$ & 0,45 \\
\hline ativo_log & $-0,6195$ & 0,22 & $-2,82$ & $0,01 *$ \\
\hline log_AI/A & 0,2099 & 0,12 & 1,82 & $0,07 *$ \\
\hline dum_d_3_rlv & 0,2987 & 0,23 & 1,30 & $0,14^{*}$ \\
\hline var_pib & $-0,1028$ & 0,04 & $-2,68$ & $0,01 *$ \\
\hline var_rlv_s15 & 0,3137 & 0,28 & 1,13 & 0,26 \\
\hline gastos_pess_log & 0,2654 & 0,24 & 1,13 & 0,26 \\
\hline Cons & $-0,0125$ & 0,01 & $-1,57$ & $0,12 *$ \\
\hline $\mathrm{r}^{2}$ within & 0,1623 & Wald chi2 & & 198,42 \\
\hline$r^{2}$ between & 0,0823 & Prob > chi 2 & & 0,0000 \\
\hline $\mathrm{r}^{2}$ overall & 0,1632 & & & \\
\hline
\end{tabular}

Análise conjunta para o Custo dos Produtos Vendidos

* Dados significativos para a presente pesquisa

Fonte: Dados da pesquisa.

Da mesma forma como realizado para o CT, a

Tabela 7 destaca apenas os fatores que são significativos na análise individual do CPV. Dos sete fatores testados, o modelo indica que quatro são significativos quando analisados em conjunto. Conforme já anunciado, trata-se dos mesmos fatores que são significativos para a explicação da assimetria do CT. Em função disso, pode-se representar a equação 3 que explica a assimetria do CPV da seguinte forma:

var_CPV $=-0,0125+\left(1,0621 * v a r \_r l v\right)+(-0,1511 *$ dum_d_1_rlv $)+\left(-0,6195 * a t i v o \_l o g * d u m \_d \_1 \_r l v\right)+(-$

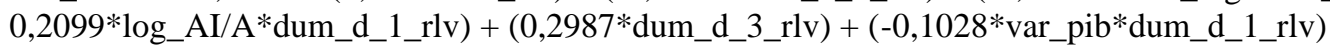

Por fim, a análise conjunta para a DVA também apresenta quatro fatores explicativos considerados significantes, porém, desta vez diferentes dos apresentados para o CT e para o CPV. Os resultados 
Tabela 8 detalham tais fatores e permitem uma visão ampla para a explicação da assimetria para as empresas brasileiras listadas na BM\&FBOVESPA.

\section{Tabela 8}

Análise conjunta para as Despesas com Vendas e Administrativas

\begin{tabular}{|c|c|c|c|c|}
\hline var_DVA & coef. & std. err. & $\mathbf{z}$ & $\bar{p}>\mathbf{z}$ \\
\hline var_rlv & 0,3977 & 0,04 & 9,21 & $0,00^{*}$ \\
\hline dum_d_1_rlv & 0,0862 & 0,05 & 1,65 & $0,09 *$ \\
\hline $\log \_$AI/A & $-0,1898$ & 0,04 & $-4,26$ & $0,00^{*}$ \\
\hline dum_d_3_rlv & 0,1527 & 0,06 & 2,56 & $0,01 *$ \\
\hline var_pib & $-0,0391$ & 0,01 & $-3,28$ & $0,00^{*}$ \\
\hline var_rlv_s15 & $-0,1219$ & 0,10 & $-1,25$ & 0,21 \\
\hline concentração & $-0,1368$ & 0,07 & $-1,93$ & $0,05^{*}$ \\
\hline Cons & $-0,0024$ & 0,00 & $-0,72$ & 0,47 \\
\hline $\mathrm{r}^{2}$ within & 0,2026 & Wald chi2 & & 565,94 \\
\hline $\mathrm{r}^{2}$ between & 0,2140 & Prob > chi 2 & & 0,0000 \\
\hline $\mathrm{r}^{2}$ overall & 0,2255 & & & \\
\hline
\end{tabular}

* Dados significativos para a presente pesquisa

Fonte: Dados da pesquisa.

Conforme a

Tabela 8, são quatro os fatores explicativos significativos na análise conjunta: o logaritmo da imobilização das empresas, a diminuição da RLV consecutivamente por 3 períodos, a variação do PIB e a concentração do capital. Assim, a compreensão da assimetria das despesas pode ser expressa pela equação 4 da seguinte maneira:

var_DVA $=-0,0024+\left(0,3977 * v a r \_r l v\right)+(0,0862 *$ dum_d_1_rlv $)+\left(-0,1898 * \log \_A I / A * d u m \_d \_1 \_r l v\right)+$ $(0,1527 *$ dum_d_3_rlv $)+\left(-0,0391 * v a r \_p i b * d u m \_d \_1 \_r l v\right)+(-0,1368 *$ concentração*dum_d_1_rlv $)$

Por fim, com base nas análises realizadas em conjunto, pode-se compreender de forma mais completa a relação entre os fatores explicativos e a assimetria dos custos das empresas. Em função dos resultados satisfatórios apresentados, em especial para o CT, os gestores podem gerenciar melhor os recursos e, consequentemente, aumentar o lucro. Os gestores e analistas financeiros que fizeram previsões de vendas e lucros durante o período de 1996 a 2005, de acordo com Kim e Prather-Kinsey (2010), mesmo ao acertar as previsões de vendas, erraram na previsão dos lucros, por não compreenderem como os custos se comportam. Portanto, por meio das equações apresentadas, e com as previsões de vendas, que são mais assertivas, os custos também podem ser preditos e as decisões dos gestores antecipadas.

\section{CONCLUSÕES}

O presente estudo comprovou que os fatores explicativos, identificados na literatura internacional, também afetam a assimetria dos custos de empresas brasileiras, porém, em diferentes escalas, bem como a sua junção resulta em uma explicação mais robusta para os Sticky Costs. Para tal, a pesquisa determinou a influência dos fatores explicativos no comportamento assimétrico dos custos das empresas brasileiras.

Cabe destacar que as conclusões apresentadas nesta pesquisa se referem à realidade brasileira, limitada às empresas de capital aberto listadas na BM\&FBOVESPA, no período de 1995 a 2014. 
Contudo, a lógica utilizada se aplica às mais diversas realidades, sendo necessário apenas o alinhamento dos fatores explicativos.

Após a revisão da literatura, em que se mapeou diversos fatores explicativos para a assimetria dos custos, e com base nas conclusões dos estudos já realizados, pode-se definir 12 hipóteses para a presente pesquisa. Estas se referem a fatores identificados em economias e tempos diversos, em que muitos não foram testados empiricamente, ou tampouco em economias emergentes, como é o caso do Brasil, cujos estudos desta natureza ainda são incipientes.

Para a assimetria, os resultados da presente pesquisa apontaram que quando a RLV aumenta $1 \%$, o CT aumenta $0,74 \%$. Porém, quando a RLV reduz $1 \%$, esses mesmos custos reduzem apenas $0,68 \%$. Ou seja, os custos totais das empresas brasileiras possuem comportamento Sticky no período analisado. Para o CPV e DVA os resultados também indicaram assimetria dos custos. Portanto, podese concluir, com base na análise do CT que as empresas brasileiras possuem comportamento similar aos achados na literatura internacional, principalmente em relação aos estudos de Anderson et al. (2003), Calleja et al. (2006), Yükçü e Özkaya (2011), Porporato e Werbin (2012), Werbin et al. (2012) e Kokotakis et al. (2013).

Dos fatores analisados, pode-se concluir que alguns possuem bom poder explicativo para os Sticky Costs e outros para os Anti-Sticky Costs. Em relação aos Sticky Costs, são fatores com influência significativa: setor de atuação; tamanho da empresa; intensidade do uso de ativos; pessimismo dos gestores; ambiente macroeconômico; magnitude das variações da RLV; intensidade do uso de mão de obra (CPV) e atraso nos ajustes (períodos de 3 anos). Alguns fatores, inclusive, possuem coeficiente $\beta_{2}$ elevado, como $-0,23$ da magnitude das variações e $-0,16$ da intensidade do uso de ativos, ou seja, que contribuem mais significativamente para o surgimento dos Sticky Costs nas empresas pesquisadas. Assim, o presente estudo contribui para o avanço das pesquisas sobre o tema, com base em um conjunto de possíveis fatores explicativos identificados na literatura internacional. Apresenta, ainda, uma lista daqueles que, de fato, afetam de maneira individual o comportamento dos custos de empresas brasileiras.

Por fim, com a formulação da hipótese conjunta $\left(\mathrm{H}_{12}\right)$, pode-se concluir que, com a análise conjunta dos fatores explicativos, que já se apresentaram significativos de forma individual, os resultados refletem de maneira mais completa o comportamento dos custos de empresas brasileiras, em especial, as causas da sua assimetria. Portanto, com o modelo de análise conjunta gerada para o CT, CPV e DVA, os gestores dispõem de uma importante técnica de previsão do comportamento dos custos, com base em variáveis externas e de conhecimento público.

Ao se analisar todas as variáveis simultaneamente, percebeu-se que os fatores significativos foram os mesmos apresentados, tanto para o CPV, quanto para o CT. Esse fato direciona uma das principais contribuições do estudo, qual seja, a indicação de uma lista de fatores que explicam a assimetria dos custos de empresas brasileiras. Mas que não, necessariamente, são os mesmos identificados no cenário internacional, uma vez que no Brasil, pelas diversas características apresentadas no decorrer da pesquisa, tem-se um ambiente de pesquisa diverso de onde as pesquisas sobre o tema se originaram.

Enfim, em um sentido mais amplo, a pesquisa atingiu seu propósito de contribuir com a evolução da teoria sobre Costs Stickiness, ainda pouco explorada no Brasil, bem como em relação aos aspectos práticos da gestão de empresas brasileiras. Porém, após a realização deste estudo, abremse oportunidades de avanço, ainda mais, nesse campo de conhecimento. Assim, sugere-se para futuras pesquisas o aprofundamento qualitativo, em cada um dos fatores que se apresentaram significativos, para a compreensão mais detalhada da influência aqui evidenciada. Além disso, o presente estudo abre as portas para o início das discussões relativas à terceira etapa das pesquisas na área que, conforme Malik (2012), consiste na identificação das consequências do fenômeno para as empresas brasileiras. 


\section{REFERÊNCIAS}

Abu-Serdaneh, J. (2014). The asymmetrical behavior of cost: evidence from Jordan. International Business Research, 7(8), 113-122.

Anderson, M. C., Banker, R. D., \& Janakiraman, S. N. (2003). Are selling, general, and administrative costs "sticky"? Journal of Accounting Research, 41(1), 47-63.

Balakrishnan, R., \& Gruca, T. S. (2008). Cost stickiness and core competency: A note. Contemporary Accounting Research, Forthcoming, 25(4), 993-1006.

Balakrishnan, R., Labro, E., \& Soderstrom, N. S. (2014). Cost structure and sticky costs. Journal of Management Accounting Research, 26(2), 91-116.

Balakrishnan, R., Petersen, M. J., \& Soderstrom, N. S. (2004). Does capacity utilization affect the "stickiness" of cost? Journal of Accounting, Auditing \& Finance, 19(3), 283-299.

Banker, R. D., \& Byzalov, D. (2014). Asymmetric cost behavior. Journal of Management Accounting Research, 26(2), 43-79.

Banker, R. D., Byzalov, D., \& Chen, L. T. (2012). Employment protection legislation, adjustment costs and cross-country differences in cost behavior. Journal of Accounting and Economics, 55(1), 111-127.

Banker, R. D., Byzalov, D., Ciftci, M., \& Mashruwala, R. (2014). The moderating effect of prior sales changes on asymmetric cost behavior. Journal of Management Accounting Research, 26(2), 221-242.

Banker, R. D., Byzalov, D., \& Plehn-Dujowich, J. M. (2014). Demand uncertainty and cost behavior. The Accounting Review, 89(3), 839-865.

Banker, R. D., \& Chen, L. (2006). Predicting earnings using a model based on cost variability and cost stickiness. The Accounting Review, 81(2), 285-307.

Benston, G. J. (1966). Multiple regression analysis of cost behavior. The Accounting Review, 41(4), 657-672.

Blue, G., Moazez, E., Khanhossini, D., \& Nikoonesbati, M. (2013). The relationship between perspective managers and 'sticky costs' in the Tehran Stock Exchange. Social Science Research Network. doi: https://dx.doi.org/10.2139/ssrn.2216631.

Bosch, J. M. A., \& Blandón, J. G. (2011). The influence of size on cost behaviour associated with tactical and operational flexibility. Estudios de Economía, 38(2), 419-455.

Calleja, K., Steliaros, M., \& Thomas, D. C. (2006). A note on cost stickiness: Some international comparisons. Management Accounting Research, 17(2), 127-140.

Chen, C. X., Lu, H., \& Sougiannis, T. (2012). The agency problem, corporate governance, and the asymmetrical behavior of selling, general, and administrative costs. Contemporary Accounting Research, 29(1), 252-282.

Chen, J. Y. S. (2013). Implications of sticky cost behavior for earnings surprise and market reaction (Tese de Doutorado). Temple University Libraries.

Ciftci, M., Mashruwala, R., \& Weiss, D. (2016). Implications of cost behavior for analysts' earnings forecasts. Journal of Management Accounting Research, 28(1), 57-80.

Da Silva, S. S., De Sousa, A. R., \& Leite, E. T. (2011). Conflito de agência em organizações cooperativas: um ensaio teórico. Organizações Rurais \& Agroindustriais, 13(1), 63-76.

Dalla Via, N., \& Perego, P. (2013). Sticky cost behaviour: evidence from small and medium sized companies. Accounting \& Finance, 54(3), 753-778.

Guenther, T. W., Riehl, A., \& Rößler, R. (2014). Cost stickiness: state of the art of research and implications. Journal of Management Control, 24(4), 301-318.

He, D., Teruya, J., \& Shimizu, T. (2010). Sticky selling, general, and administrative cost behavior and its changes in Japan. Global Journal of Business Research, 4(4), 1-10.

Holzhacker, M., Krishnan, R., \& Mahlendorf, M. D. (2015). The impact of changes in regulation on cost behavior. Contemporary Accounting Research, 32(2), 534-566.

Ibrahim, A. E. A. (2015). Economic growth and cost stickiness: evidence from Egypt. Journal of Financial Reporting and Accounting. 13(1), 119-140.

Jalilian, M., \& Elyssai, E. V. (2014). Review and analyzing the factors affecting the stickiness behavior of general administration costs and sales of listed companies in Tehran Stock Exchange. Applied mathematics in Engineering, Management and Technology, 2(4), 584-596.

Kim, M., \& Prather-Kinsey, J. (2010). An additional source of financial analysts' earnings forecast errors: imperfect adjustments for cost behavior. Journal of Accounting, Auditing \& Finance, 25(1), 27-51. 
Kokotakis, V., Mantalis, G., Garefalakis, A., Zanidakis, N., \& Galifianakis, G. (2013). The sticky cost on Greek food, beverages and tobacco limited companies. International Journal of Economics \& Business Administration, 1(2), 49-58

Kremer, A. W. (2015). Análise de fatores explicativos para o comportamento assimétrico dos custos em ambiente regulado. (Dissertação de Mestrado) Programa de Pós-Graduação em Contabilidade. Universidade Federal de Santa Catarina.

Krishnan, R. (2015). Management accountant - What ails thee? Journal of Management Accounting Research, 27(1), 177-191.

Liang, L. I. (2013). Study of corporate governance on relation between self-interest incentive and cost stickiness. International Journal of Digital Content Technology and its Applications, 7(6), 706-715.

Malik, M. (2012). A review and synthesis of'cost stickiness' literature. Social Science Research Network. doi: https://dx.doi.org/10.2139/ssrn.2276760.

Marques, A. V. C., Santos, C. K. S., Lima, F. D. C., \& Costa, P. (2014). Cost stickiness in Latin American open companies from 1997 to 2012. European Scientific Journal, 10(10), 270-282.

Medeiros, O. R., Costa, P. S., \& Silva, C. A. T. (2005). Testes empíricos sobre o comportamento assimétrico dos custos nas empresas brasileiras. Revista Contabilidade \& Finanças, 16(38), 47-56.

Nassirzadeh, F., Saei, M. J., Salehi, M., \& Bayegi, S. A. H. A (2013). A Study of the stickiness of cost of goods sold and operating costs to changes in sales level in Iran. Studies in Business \& Economics, $8(2), 79-89$.

Noreen, E., \& Soderstrom, N. (1997). The accuracy of proportional cost models: evidence from hospital service departments. Review of Accounting Studies, 2(1), 89-114.

Pamplona, E., Fiirst, C., Silva, T. D. J., \& Zonatto, V. (2015). Comportamento dos custos das maiores empresas do Brasil, Chile e México entre 2002 a 2013 e análise dos sticky costs. In IX Congresso Anpcont. Anais... Curitiba, PR.

Pervan, M., \& Pervan, I. (2012). Sticky costs: evidence from Croatian food and beverage industry. International Journal of Mathematical Models and Methods in Applied Sciences, 8(6), 963-970.

Porporato, M., \& Werbin, E. M. (2012). Active cost management in banks: evidence of sticky costs in Argentina, Brazil and Canada. International Journal of Financial Services Management, 5(4), 303320 .

Richartz, F., \& Borgert, A. (2014). O comportamento dos custos das empresas brasileiras listadas na BM\&FBOVESPA entre 1994 e 2011 com ênfase nos sticky costs. Contaduría y Administración, 59(4), 39-70.

Richartz, F., Borgert, A., Vicente, E. F. R., \& Ferrari, M. J. (2012). Comportamento dos custos das empresas brasileiras listadas no segmento de fios e tecidos da BM\&FBOVESPA entre 1998 e 2010. In Anais do Congresso Brasileiro de Custos - $A B C$, Bento Gonçalves, RS.

Richartz, F., \& Ensslin, S. R. (2013). Comportamento dos custos: mapeamento e análise sistêmica das publicações internacionais. In Anais do Congresso Brasileiro de Custos - ABC, Uberlândia, MG.

Shahnazari, E., Talebnia, G., \& Jamei, R. (2013). Study of adjusted profit and productivity forecast error of bazaar with using of cost behavior. Life Science Journal, 10(1), 684-694.

Subramaniam, C., \& Weidenmier, M. L., (2003). Additional evidence on the sticky behavior of costs. Social Science Research Network. doi: https://dx.doi.org/10.2139/ssrn.369941.

Weiss, D. (2010). Cost behavior and analysts' earnings forecasts. The Accounting Review, 85(4), $1441-1471$.

Werbin, E. M. (2011). Los costos pegadizos (sticky costs): una prueba empírica en bancos argentinos. Revista Iberoamericana de Contabilidad de Gestión, 7(14), 1-9.

Werbin, E., Vinuesa, L. M. M., \& Porporato, M. (2012). Costos pegajosos (sticky costs) en empresas españolas: un estudio empírico. Contaduría y Administración, 57(2), 185-200.

Xi, F., Liu, X., Wang, Q., \& Liang, M. (2013). Empirical research of the cost stickiness behavior under opportunism incentives. Information Technology Journal, 12(19).

Yasukata, K. (2011). Are 'Sticky Costs' the result of deliberate decision of managers? Social Science Research Network. doi: https://dx.doi.org/10.2139/ssrn.1444746

Yükçü, S., \& Özkaya, H. (2011). Cost behavior in Turkish firms: are selling, general and administrative costs and total operating costs "sticky"? World of Accounting Science, 13(3), 1-28. 